D.E.L.T.A., Vol. 15, N. ${ }^{\circ}$ EsPECIAL, 1999 (105-146)

\title{
TRINTA ANOS DE SINTAXE GERATIVA NO BRASIL*
}

(Thirty Years of Generative Grammar in Brazil)

\author{
Mary A. Kato (UNICAMP)** \\ Jânia RAmOS (UFMG/CNPq)
}

ABSTRACT: This paper reports the generativist research developed in Brazil, from the standard theory to the Minimalist approach (Chomsky 1995), leaving out works in language aquisition, which are reported in Kato (1999). It contains three sections: I. The Standard Theory and the Extended Standard Theory; II. The Principles and Parameters Theory; III. The years 1998-1999.

KEY WORDS: Generative Grammar, Principles and Parameters; Chomsky.

Palavras-chave: Gramática Gerativa; Princípios e Parâmetros; Chomsky.

I. Primeira Parte: A Teoria-Padrão (TP) e a Teoria-Padrão Estendida (TPE) ${ }^{1}$

1. A formação de sintaticistas no período da TP e TPE

A primeira notícia no Brasil sobre gramática gerativa veio de dois artigos publicados na revista Tempo Brasileiro, em 1967, um de Lemle e outro de Mattoso Câmara, no qual esse último afirmava ser o gerativismo uma variedade do estruturalismo. O primeiro curso de gerativa no Brasil foi ministrado por Sara Gudschinky, em 1994, na UnB. Mais tarde, a teoria é apresentada por Míriam Lemle, no Museu Nacional; por Heles Contreras no I Instituto de Lingüística em 1968; por John Martin, em vários Institutos Brasileiros de Lingüística e depois na PUC-SP. As primeiras teses seguindo esta teoria foram as de Eunice Pontes (1969/ 1973) sobre verbos auxiliares no português; de Leila Barbara (1971/1975) sobre asseveração e não-asseveração; e de Mary Kato (1972/1974) sobre a semântica do artigo definido. A partir de então, a sintaxe na linha gerativa passa a ser ministrada também por professores que

\footnotetext{
* A segunda parte do trabalho é uma expansão de KATO (no prelo) a sair na REVISTA DA $A L F A L$. Os trabalhos no prelo e não publicados foram excluídos, nesta versão, dada a limitação de páginas. Agradecemos a Mario Perini e Aryon Rodrigues pelos depoimentos sobre o período relatado na Primeira Parte. Agradecemos a Ana Paula Scher, Helena Britto e Marina Augusto, pela revisão da parte incluída na Segunda Parte.

** A autora contou com bolsa CNPq (Proc. 300814/88-89 renov.) e Auxílio FAPESP (Proc. 98/13726-8).

${ }^{1}$ Consulte-se Naro (1976) para uma boa retrospectiva do período.
} 
obtiveram sua formação parcialmente no Brasil e parcialmente no exterior, através de Institutos e estágios.

Até 1974, o ensino e a pesquisa da gerativa dependiam muito de professores e orientadores estrangeiros, em geral americanos. Vários passaram por aqui: John Martin, Mercedes Roldan, Carl Harrison, Marianne Esztergar, Frank Brandon, Quentin Pizzini, Anthony Naro, Christian Rohrer. Naro, conforme depoimento de Perini, foi, dos estrangeiros, o mais importante; aqui se radicou e permaneceu, formando toda uma geração no Rio não só de gerativistas, mas também, e sobretudo, de variacionistas. John Martin teve também certa influência no início, tendo passado pela PUC-SP, PUC-Campinas, UNICAMP e PUC-PR.

Na década de 1970, havia alguns brasileiros estudando gerativa no exterior: Antônio Carlos Quicoli, na Universidade de SUNY, Buffalo, o primeiro brasileiro a obter Ph.D. na área, Milton Azevedo, na Universidade de Cornell e Perini, na Universidade do Texas ${ }^{2}$. Com o retorno de Quicoli e de Perini, cresce o espaço da área. Quicoli vai para a UFRJ e depois para a UNICAMP e em 1978 deixa o país. Perini, que havia voltado para a UFMG, é contratado pela UNICAMP. No Rio, Margarida Basílio ${ }^{3}$ e Mariza Pimenta-Bueno iniciam sua atuação, após terem concluído doutorado, respectivamente, na Universidade do Texas e na Universidade de Stanford ${ }^{4}$.

Têm início, assim, quatro pólos principais de estudos gerativos: UFRJ, PUC-SP, UNICAMP e UFMG. Na UFRJ tem andamento pesquisas orientadas por Naro, Lemle e Basílio. Na PUC-SP formam-se pesquisadores sob a orientação de Mary Kato e Leila Barbara. Em Campinas, sob a orientação de Quicoli, Pizzini e Brandon, desenvolvem-se várias pesquisas. Na UFMG, Eunice Pontes, após publicar suas duas teses, continua suas atividades ao lado de Perini, indo exercer seu papel de formadora também na UnB.

As obras didaticamente mais importantes foram o livro de Perini (1976) sobre a TP com análises do Português e o de Lemle (1984) sobre o período da TPE. Não se pode deixar de referir, aqui, a publicação dos Anais do Encontro

\footnotetext{
${ }^{2}$ Vide Quicoli (1972), Azevedo (1973) e Perini (1974).

${ }^{3}$ Basílio se dedica à area da morfologia derivacional, sub-área que não faz parte da cobertura deste trabalho.

${ }^{4}$ Não se pode deixar de mencionar aqui o papel importante que Aryon Rodrigues teve na contratação dos professores estrangeiros e no envio dos lingüistas brasileiros aos Estados Unidos para se doutorarem na área.
} 
Nacional de Lingüística da PUCRJ, que, até 1986, ofereceram um painel abrangente de quais eram as pesquisas realizadas e em andamento e de quem fazia lingüística no Brasil.

2. As linhas de pesquisa privilegiadas

\subsection{Léxico e sintaxe}

Um grupo de pesquisadores tem como objeto a decomposição lexicosemântica de verbos, de modo a correlacionar papel semântico dos argumentos ao tipo de complementação: causativas e incoativas (Lier, 1977; Votre, 1976); modais (Miranda, 1975; Lobato, 1978, 1979); verbos "dar", "fazer", "tomar", "ser", "estar" (Berthier, 1974); verbo "começar" (Azevedo, 1977a); o verbo "esquecer-se" (Oliveira, 1975); verbo "sujar" (Decat, 1978a); verbos de percepção (Barros, 1977); modo verbal (Pereira, 1974; Fávero (1974,1982), e tempo verbal (Corôa, 1983); Trieweiler, 1976); auxiliares (Vasconcelos, 1976 e Madureira, 1975); verbos de experiência (Mioto, 1975); verbos denominais (Arrais, 1981), verbos transitivos (Kato, 1976b) etc.

\subsection{Estrutura sintática do português}

\subsubsection{Sintagma nominal}

Foram objeto de estudo as regras que convertiam NPs em pronomes e indicavam o sentido e escopo do movimento: pronominalização (Mioto,1975; Almeida,1977; Alves, 1975; Gamarsky, 1974; Martins, 1976; Oliveira, 1978; Silva, 1975; Ikeda, 1977; Steiner, 1978); posição do adjetivo no sintagma nominal (Pazzini, 1978); gradação de adjetivos (Vannucchi, 1977); regras de expansão de constituintes (Lemle, 1978; Lemle e Naro, 1977);. movimento de quantificadores (Maia, 1975; Simões, 1974); possessivos (Campos, 1977; Perini, 1977); determinantes (Pontes, 1976); complemento nominal (Shibao, 1977; Pereira, 1978; Schaff Filho).

\subsubsection{Estrutura da oração simples}

Em relação à passiva, buscavam-se evidências de diferenças semânticas entre as estruturas superficiais em relação às ativas com o propósito de mostrar que provêm de estruturas subjacentes distintas (Cunha, 1978; Arruda, 1978; Vieira, 1978; Branco, 1979; Nascimento, 1978). 
Já em relação ao sujeito, foram objeto de análise a formulação de regras de supressão, movimento do NP sujeito e posição desse NP na estrutura profunda (Menezes, 1979; Teixeira, 1977; Kato, 1977); elipse (Kato, 1976a,1981; Pimenta-Bueno, 1981b; Bittencourt, 1979; Gomes, 1975; Figueiredo, 1975).

Sobre concordância verbal, trabalharam Humberto (1975); Veado (1981); Martin (1975); Tondo (1976), entre outros.

Sobre movimentos e deslocamentos, foram analisados sintagmas deslocados em afirmativas (Carvalho, 1975); construções SA-Adj-Sprep (Brisolla, 1980; Bisol, 1972) e as interrogativas-Q (Decat, 1978b, 1980; Alvarenga, 1981).

Em relação a classes de palavras, foram estudados sob o ponto de vista sintático os predicados adjetivais (Alkmin, 1975); advérbios (Saraiva, 1979; 1980; Parisi, 1977); negação (Brenner, 1977; Kneipp, 1978; Brandon, 1976) e preposições (Sousa, 1977; Saliba, 1983); auxiliares (Tavares de Macedo, 1977); e particípios (Pimenta-Bueno, 1981a).

\subsubsection{Estruturas oracionais complexas}

Investigaram-se vários tópicos relacionados a orações subordinadas: fronteira entre orações (Rodrigues, 1975); orações relativas (Cardoso, 1976; Mollica, 1977; Samara, 1976; Silva, 1977; Cohen, 1982; Pizzini, 1979); orações finais (Waldrep, 1981); comparativas (Romualdo, 1975; Fontes, 1978); infinitivo flexionado (Moraes, 1971); modo verbal (Perini, 1978). Sobre orações coordenadas vide De Filipo (1977).

\subsection{Comparação de línguas}

Comparações detalhadas entre construções do inglês e do português foram apresentadas com diferentes propósitos, tendo um sido o ensino de línguas, e o outro, o avanço da teoria gramatical. Os tópicos são: preposições (Ramos, 1973; Schmitz, 1977); tempo verbal (Cerqueira, 1984); ordem dos adjetivos no sintagma nominal (Lemle, 1979); formas gerundivas (Pereira, 1979); subordinadas adverbiais no francês e no português (Machado, 1979); orações relativas no português e no francês (Viana,1977); clíticos em espanhol e em português (Senday, 1975); negação no inglês e no português (Fiad, 1975); "tag questions" no inglês e português (Cavalcante, 1972); estruturas iniciadas com verbo no inglês e no português (Szabo,1977); estruturas comparativas do 
inglês e do português (Fontes, 1978); estruturas complexas do português e do inglês (Rocca, 1978), dentre outros.

II. Segunda Parte: A Teoria de Princípios e Parâmetros

\section{A formação de sintaticistas na linha da TPP}

Duas teses defendidas na França por brasileiros de Minas Gerais (UFMG, Belo Horizonte) iniciam a abordagem da TPP no Brasil: a de Milton do Nascimento (1984), sobre a posposição do sujeito no PB, e a de Moreira da Silva (1983), sobre a assimetria de comportamento entre o sujeito e o objeto no PB. Embora defendidas na França, faz-se menção a esses trabalhos por terem plantado a semente para muitas das questões que seriam tratadas depois no Brasil.

Uma outra lingüista formada na França, Charlotte Galves (da UNICAMP) é também uma deslanchadora de pesquisas sintáticas na visão da TPP. Muitas das questões com que a perspectiva gerativista vem trabalhando no Brasil, como, por exemplo, o fenômeno do objeto nulo referencial (Galves, 1984) ou as peculiaridades das construções com se (Galves, 1986a) e o enfraquecimento da concordância (Galves, 1993), foram tópicos por ela tratados inicialmente.

Em 1988, após sua estadia de pós-doutorado na França, Lúcia Lobato (da Universidade de Brasília) lança seu livro-texto (com manual) sobre a teoria da Regência e Ligação (Lobato, 1988a), que ajudou enormemente professores e alunos a ensinarem e a aprenderem a TPP. Em 1992, sai em Portugal o livro de Eduardo Raposo sobre a mesma teoria, obra que vem complementar, com dados do Português Europeu (PE), o livro de Lobato.

Juntam-se a esses a seguir quatro lingüistas da geração que havia passado por outras escolas e vertentes teóricas como o estruturalismo, gerativa-padrão, padrão estendida, semântica gerativa, gramática relacional e gramática categorial: Miriam Lemle (da UFRJ), Yonne Leite (do Museu Nacional), Carlos Franchi e eu (ambos da UNICAMP). Miriam Lemle continua a trabalhar na UFRJ, mas na perspectiva TPP. Yonne Leite deslancha, no Museu Nacional, com sua colega Bruna Franchetto, de formação italiana, o estudo de línguas indígenas na visão da TPP. O colega Franchi, embora se declarando até hoje um céptico da gramática gerativa, atraiu, com seu discurso filosófico e brilhante, muitos alunos para a área e atuou fortemente na formação de sintaticistas. Quanto a mim, depois de um tempo afastada da teoria, decepcionada por um 
modelo de gramática que se limitava a estudar restrições às regras, voltei a fazer gerativa, na década de 80, após fazer uns cursos com Rizzi, Safir, Whitman e outros no Instituto da LSA de 1986, na CUNY, atraída com as ricas possibilidades da versão de parâmetros na descrição empírica dos fatos lingüísticos.

Mais tarde, entra no cenário Esmeralda V. Negrão (da USP), com Ph.D. dos Estados Unidos, com tese sobre "controle" (Negrão, 1986). Há também doutores formados no Brasil começando a atuar na graduação e na pósgraduação, na área da sintaxe. Entre eles, por exemplo, os seguintes exdoutorandos da UNICAMP: Carlos Mioto (UFSC), Jânia Ramos, Márcia Cançado e Eunice Nicolau (UFMG), Ilza Ribeiro (UEFS), Márcia D Vieira e Marília Facó Soares (Museu Nacional), Sonia Cyrino (UELondrina), Maria Aparecida Torres Morais (USP), M. Eugênia L. Duarte (UFRJ), Vicente Cerqueira (UFAcre), Maria Aparecida Lopes Rossi (Faculdade de Taubaté), Rosane de Andrade Berlinck (UNESP) e muitos outros a caminho. Mais recentemente, houve o retorno de alunos que fizeram mestrado no país e que voltaram com Ph.D. do exterior, tendo sido já absorvidos pelos programas de pós-graduação do país. São eles: Lorenzo Vitral (UFMG), com doutorado da França, Maria Cristina Figueiredo (UFSC), com doutorado de Genebra, Jairo Nunes (UNICAMP), com doutorado dos Estados Unidos, Sergio Menuzzi (PUCRS) com doutorado da Holanda e outros também a caminho.

É assim, em Belo Horizonte, em Campinas, em Brasília, no Rio, em São Paulo e em Santa Catarina que se passou a ter os pólos principais de investigação lingüística na linha da TPP.

\section{Teoria e dados}

A gramática gerativa tem se centrado em dois tipos de pesquisa. O primeiro tipo tem a ver com os princípios e o segundo com os parâmetros, embora nem sempre seja fácil distinguir um do outro, pois muitos dos parâmetros são associados a determinados princípios.

O português, à primeira vista, apresenta, ainda, outros fenômenos que fazem duvidar de certos princípios e conceitos dentro da TPP, como é, por exemplo, o caso do domínio dos pronomes (Princípio de Ligação). Enquanto línguas como o inglês apresentam uma distribuição claramente complementar dos pronomes pessoais e dos reflexivos, o PB não apresenta uma distinção tão clara Os trabalhos de Galves (1986b) e (1997) - o primeiro em resposta a 
Lemle (1985) - abordam esse fenômeno. Também em relação a reflexivos (anáfora, na terminologia chomskiana), Franchetti (1997a e 1997b ) levanta problemas sobre o que considerar um item anafórico.

Problemas na teoria do controle são examinados por Negrão (1989), a partir de dados do PB. Também o Princípio da Categoria Vazia (PCV) e o Princípio da Subjacência são discutidos por Lobato (1988b), com dados do PB.

As línguas indígenas também têm sido uma fonte de questões teóricas como, por exemplo, o problema levantado por Franchetto (1996) sobre o conceito de ergatividade; o problema do fenômeno da incorporação como um processo sintático levantado em Leite (1995); o problema da anáfora à longa distância discutido em Vieira (1997a).

Outra tarefa para os pesquisadores gerativistas é estudar como os diversos parâmetros postulados na teoria têm seus valores fixados em [+] ou [-] nas línguas. Os trabalhos brasileiros têm-se concentrado principalmente nessa tarefa, mas seus estudos apresentam uma característica própria. Além de estudos de cunho estritamente gerativista, com dados introspectivos, grande parte dos trabalhos são baseados em dados empíricos. Assim, em lugar de usar dados já estudados por outras vertentes teóricas ou usar exclusivamente dados de introspecção, nossa sintaxe sincrônica é rica em dados do dia-a-dia, que o lingüista grava ou escuta. Alguns autores assumem explicitamente "um casamento" entre a teoria gerativa e a metodologia variacionista, como é a linha seguida na UNICAMP por alguns professores, cujas idéias podem ser lidas em Tarallo \& Kato (1989). Em trabalho mais recente de Ramos (1992 e 1997a), há uma reflexão sobre as afinidades e diferenças entre Chomsky e Labov. Foi essa forma de pesquisar que permitiu a Tarallo e Kato iniciar um projeto em diacronia, como se verá mais abaixo, e outro na área da Gramática do Português Falado ${ }^{5}$, mais especificamente de uma sub-parte desse projeto (Sintaxe II/Relações Gramaticais).

\section{As linhas de pesquisa privilegiadas}

Podem-se distinguir as seguintes linhas de pesquisa:

\subsection{Estudos sobre a estrutura do português}

${ }^{5}$ A Gramática como um todo foi idealizada e coordenada por Ataliba de Castilho (USP) e seus resultados podem ser vistos nos 6 volumes da Gramática do Português Falado, publicados desde 1990, pela Editora da UNICAMP, com suporte da FAPESP. 


\subsubsection{Relações léxico-sintáticas}

Três trabalhos teóricos podem ser citados aqui: o de Lobato (1994a), o de Dillinger \& Nascimento (1994) e o de Franchi (1997), que discutem, já numa visão Minimalista, a relação entre o léxico e a sintaxe, a possibilidade de eliminação do léxico como uma interface e a possibilidade das propriedades poderem ser deriváveis na interface da Forma Lógica com os sistemas conceituais-intencionais.

Nessa área da pesquisa se inscrevem os trabalhos de Whitaker Franchi (1989) acerca de verbos ergativos e de Cançado (1995a e 1995b) sobre verbos psicológicos. Outro trabalho na mesma linha é o de Viotti (1997) sobre as relações temáticas com o verbo ter. Usando a visão de Jackendoff (1990), Chagas de Souza (1997) analisa o caso dos causativos implícitos do PB.

Levantando a interessante questão da projeção de itens morfologicamente complexos como V-DO, Pires (1996) indaga sobre a natureza desse elemento. Também a estrutura argumental/temática problemática de adjetivos como fácil é analisada por Lobato (1989a). Outros casos de predicação não-verbal são analisados por Freitas (1991).

\subsubsection{Sobre o Sujeito Nulo}

A distribuição do Sujeito Nulo é um dos tópicos mais explorados. Os trabalhos sincrônicos são, em geral, de cunho teórico e procuram discutir o problema do licenciamento do sujeito nulo no PB, o qual, segundo o trabalho diacrônico de Duarte (v. abaixo), está deixando de ter uso referencial. São eles: o trabalho de Galves (1987), que já mostrava a diferença entre o licenciamento do sujeito nulo no PB e no PE; o de Figueiredo Silva (1996), que estuda o fenômeno em relação a uma proposta geral de estrutura da oração, atribuindo o valor de variável ao nosso sujeito nulo; o de Kato et alii (1996), que interpreta o sujeito nulo como um apagamento em Forma Fonética (FF); o de Galves (1993), que o analisa na perspectiva de sua hipótese geral de concordância fraca no PB; o de Negrão (1997a), que examina principalmente o fenômeno do sujeito nulo não-referencial, tratando-o como variável presa a um quantificador, em posição A'; o de Novaes (1996), que procura examinar as propostas anteriores, inclusive a proposta do sujeito nulo do tipo que têm as línguas de tópico zero, fazendo uma incursão pelo Minimalismo; e o de Nicolau (1995, 1997), que também procuram reinterpretar o fenômeno do licenciamento do sujeito nulo referencial numa perspectiva Minimalista. Consta, ainda, uma tese de mestrado de Mourão (1996) sobre esse mesmo tópico. 
Com tipos diferentes de dados e de análise, esses trabalhos mostram que o tópico ainda está aberto a muitas discussões.

\subsubsection{Sobre a Inversão Verbo Sujeito}

Desde o trabalho clássico de Nascimento (1984), o problema da inversão VS no PB apresentou desafios. A restrição de mono-argumentalidade é demonstrada por Kato (1993a) como não sendo exclusiva da inversão livre, mas também abrangendo construções do tipo V2 e também as de deslocamento à direita com resumptivo nulo. A autora reanalisa todas essas ordens VS como falsas inversões. O tópico já merece um tratamento Minimalista em Vitral (1994), que o estuda em relação ao fenômeno da concordância. A inversão VS merece atenção ainda, no contexto de reduzidas de gerúndio, no estudo de Britto (1994), onde não há concordância. Um trabalho que procura verificar a relação entre o sujeito nulo e a inversão livre é o de Nicolau (1995), que analisa essas duas propriedades do parâmetro do sujeito nulo como fenômenos independentes.

Veja-se ainda o trabalho empírico sobre sujeito nulo e inversão no corpus NURC em Kato, Nascimento et alii (1996).

\subsubsection{Sobre o objeto nulo no PB}

Desde o trabalho de Huang (1984) para o chinês e de Raposo (1986) para o PE, a possibilidade de objeto nulo referencial passou a apresentar enorme interesse para a sintaxe brasileira, que contava com um objeto nulo de ocorrência muito menos restrita do que no chinês ou no PE. Wheeler (1981) já havia percebido esse fenômeno antes do advento da TPP, e Galves (1984) analisa o fenômeno dentro dessa linha, dando estatuto de pronome vazio a essa lacuna e refazendo essa análise (cf. Galves, 1989) ao longo de sua pesquisa. Kato (1993b) analisa o objeto nulo como um clítico nulo, e Kato (1996a) analisa o item lexical ele na posição de objeto como resultado de duplicação desse clítico nulo. Cyrino (1996), cujo trabalho diacrônico será visto mais adiante, faz uma retrospectiva dos estudos sobre o objeto nulo no português. Há também duas teses de mestrado abordando o assunto: a de Vanetti (1988) e a de Assunção (1993).

Além do objeto nulo, tem-se, ainda, os trabalhos de Cyrino (1997a e 1997b) sobre objetos indiretos nulos e elipse de VP, fenômeno relacionado. 


\subsubsection{Sobre fenômenos nas margens sentenciais}

As construções interrogativas, e o movimento do elemento-Q acompanhado ou não de V, mereceram um debate, na D.E.L.T.A., entre Kato (1987) e Lobato (1988c), tendo havido ainda um "follow-up" em Kato (1992). Mioto (1994) estuda o fenômeno, já dentro da proposta do critério-wh, de Rizzi (1991), de que o movimento do elemento-Q e o do verbo são morfologicamente determinados. O mesmo autor, (Mioto, 1997b), estudou, ainda, a correlação entre as formas com "é que" e "que". Ribeiro (1996a) trabalha com o mesmo tópico (o critério-wh, de Rizzi), já usando a noção de traços fortes e fracos, na visão minimalista. Uma análise empírico-gerativista pode ser vista em Sikansi (1994). O trabalho de Rocha (1990) já é uma comparação entre as interrogativas indiretas e as relativas livres. As interrogativas-Q foram ainda examinadas, em um estudo experimental sobre ilhas para extração, por Augusto (1994). O problema da extração é também examinado por Britto (1997a), que estuda o caso das copulares e suas estruturas inversas. Modesto (1995) faz uma análise original das clivadas e pseudo-clivadas. Sobre construções-Q, em geral, merece atenção ainda o estudo empírico de Kato, Braga et alii (1996), que analisa, em um só estudo, interrogativas, clivadas e relativas, em corpus oral.

Sobre tópico, ou deslocamento à esquerda, podem-se mencionar alguns trabalhos, deixando outros para a seção de estudos comparativos. Com base em um INFL implodido, Galves (1993) analisa o tópico como sujeito de AGR e associa o fenômeno ao enfraquecimento da concordância. Figueiredo Silva (1996), por outro lado, introduz o tópico em uma projeção acima do IP, em TopP, uma projeção distinta do lugar onde se posiciona o Foco sentencial. O trabalho de Modesto (1996) propõe que tanto Tópicos como Focos podem ser ou gerados in-situ, ou movidos para uma posição deslocada. Kato (1998) propõe o deslocamento como resultado de movimento de um predicado secundário, quando ele não apresenta um núcleo regente (tópico pendente).

\subsubsection{Sobre a estrutura do DP}

Há ainda estudos interessantes sobre a estrutura dos sintagmas nominais. A posição do possessivo e da frase genitiva PP é assunto de diferentes análises teóricas em Cerqueira (1995) e Müller (1996). O mesmo tema é tratado em Prado (1997). Pondé (1996) estuda a estrutura argumental dos denominais e Castro (1997) trata de categorias vazias no interior do DP. Em relação à ordem dos adjetivos, consta uma disssertação de mestrado sobre sua ordem, de Boff (1991) e um artigo de Nunes (1997). Sobre determinantes, consulte-se, ainda, o 
trabalho de Guimarães (1997a).

Também a complementação do nome mereceu uma dissertação de mestrado. Trata-se de Jorge (1986), que revê a distinção entre complemento nominal e adjunto adnominal sob a luz da TPP.

\subsubsection{Sobre complementação}

Além do objeto nulo, há ainda outros estudos que lidam com domínio da complementação, tais como o estudo sobre complementos inacusativos/ ergativos de Nuñes Costa (1989); de Nascimento e Kato (1995); de Duarte (1993); e de Negrão (1992), este para um tipo especial de construções inacusativas: as que contêm uma oração relativa.

Há ainda um interessante estudo sobre objetos nus de Saraiva (1996). De Matos (1991), tem-se um estudo sobre a complementação de verbos de percepção

Como não podia deixar de ser, complementos infinitivos merecem a atenção de vários estudiosos. Incluem-se aqui também aqueles que trabalham com o infinitivo em contextos que poderíamos chamar de adjunção, mas que podem ser tratados como completivas de preposição. Em ordem cronológica, tem-se: o trabalho de Ribeiro (1988, 1989); o de Galves (1992); o de Botelho Pereira \& Roncarati (1993); o de Silveira et alii (1994); o de Luz (1994, 1997); o de Figueiredo Silva (1997) e o de Nunes \& Raposo (1997). Sobre complementos subjuntivos, confira-se Santos (1996). Orações infinitivas e subjuntivas apresentam um problema comum de dependência nominal ou temporal, fenômeno estudado na sub-teoria de "Controle" na TPP. Estudos específicos sobre problemas de controle e complementação no PB são encontrados em Negrão (1986) e Negrão \& Müller (1996). Um estudo sobre complementação predicativa é o de Gonçalves Pinto (1991), sobre o predicado verbo-nominal. Dentro do projeto da Gramática do Português falado, já mencionado, há um trabalho extenso sobre a complementação, no corpus NURC, de Dillinger, Galves , Pagotto e Cequeira (1996), com uma interpretação na linha da TPP.

Um tópico que também pode se enquadrar como sendo de complementação é o de Kato \& Castilho (1991) que, pouco convencionalmente, tratam advérbios modalizadores como núcleos predicadores com uma sentença como complemento. 
Embora não se possa caracterizar como complementação no sentido estrito, inclui-se aqui também o trabalho sobre construções comparativas de Menezes (1989).

\subsubsection{Sobre a inter-relação sintaxe-morfologia}

Muitos estudos diagnosticam algum fenômeno sintático como relacionado à morfologia fraca do PB. Mas há também trabalhos que focalizaram a concordância como o principal fenômeno. Um dos trabalhos é o de Botelho Pereira (1984), sobre gênero e número no PB. Outro trabalho é o de Lobato (1994b) sobre a interpretação de uma análise variacionista de concordância nominal sob a ótica da TPP.

Trabalhos sobre clíticos são os que tipicamente trabalham com um problema morfo-sintático. Mas o problema intrigante é a sua posição. Por que teríamos, nas línguas românicas, a célebre Lei de Tobler-Mussafia, que exigia clíticos em segunda posição, da mesma forma que nas línguas germânicas há o requisito do verbo em segunda posição? Que núcleo funcional é responsável pelo seu posicionamento? A posição original do objeto é ocupada por um vestígio ou um pro? Por que algumas línguas admitem ênclise e outras não? Qual a diferença entre um pronome fraco e um clítico?

Todas ou algumas dessas questões estão envolvidas nos trabalhos sobre clíticos. É o caso dos trabalhos de Galves, nesses últimos anos. Veja também o trabalho de Silveira (1996).

Um trabalho interessante é o que envolve o comportamento curioso do pronome você e suas variantes ocê e cê. Vitral (1996) trata o problema do ponto de vista da gramaticalização e Ramos (1997b) considera que o estatuto de cê é de um clítico. Nunes (1994b) mostra que há, na verdade, uma redução fonológica geral do paradigma dos pronomes nominativos e Kato (1996b) propõe que o PB tem nesses pronomes enfraquecidos o seu paradigma de pronomes fracos, havendo semelhança com o que houve no francês antigo (JOU>je).

O problema da realização morfológica de caso é um tópico abordado por Ramos (1997c) trabalhando com sintagmas nominais quantificados.

Incluímos sob esse tópico também o estudo sobre passivas de Chaves (1997), cujo tratamento enfatiza o papel das categorias funcionais. 
A morfologia está intimamente ligada à conceituação de categorias. Além disso, um dos problemas que toda teoria sintática formal enfrenta é o de definir o conjunto de categorias. A definição de certas categorias enfrenta um problema maior do que a definição de outras. É o caso, por exemplo, da classe dos advérbios ${ }^{6}$ e das preposições.

Assim, dentro desse tópico podemos citar o de Salles (1992) que distingue PPs selecionados e não selecionados pelo núcleo verbal. Também Berg (1996) discute a natureza categorial das preposições. Sobre a classe dos advérbios, há ainda o trabalho de Oliveira (1996). Outro estudo é o de Moutella (1995) sobre o gerundivo, que a autora define como um núcleo Aspectual.

\subsection{Estudos Comparativos}

\subsubsection{Sobre sujeito nulo}

O trabalho de Duarte (1997) compara o fenômeno do sujeito nulo no PB e no PE e o de Oliveira (1997) o compara com o italiano. Ambos os trabalhos mostram que o PB privilegia o preenchimento.

\subsubsection{Sobre as margens sentenciais: as chamadas posições A'}

Esse tópico também tem merecido uma certa atenção na sintaxe comparativa do PB. Desde o trabalho clássico de Pontes (1987), o PB tem sido comparado às línguas orientais, como uma língua de proeminência de tópico. Isto quer dizer, em termos da TPP, que há um uso irrestrito de deslocamento à esquerda, propriedade essa correlacionada com a possibilidade de objeto nulo referencial. Kato (1989), comparando o PB com o japonês, analisa o sujeito posposto e interno a VP como correlato ao sujeito com -ga em japonês e o sujeito externo a VP como correlato ao sujeito com -wa, correspondendo essas distinções à oposição juízo categórico vs. tético de Kuroda (1976). No estudo de Kato \& Raposo (1996), os autores comparam construções de foco, de tópico e interrogativas do PE e do PB. Retomando a visão de Kuroda (op. cit.), temos o trabalho de Britto (1996), que propõe SP como o lugar do deslocado e analisa as estruturas com deslocamento, no PB, como a representação do juízo categórico.

As orações interrogativas, com pronome interrogativo, foram analisadas,

${ }^{6}$ V., por exemplo, os trabalhos sobre advérbios em: CASTILHO, A. (org.) (1990) e ILARI, R. (org.) (1992). 
do ponto de vista comparativo, em três línguas românicas, por Mioto (1989): o espanhol, o PE e o PB. Essas mesmas construções mereceram, ainda, um estudo de Menuzzi (1994), que compara PB e PE, atribuindo à existência ou não do movimento do verbo para COMP um valor paramétrico.

Há ainda um trabalho sobre relativas em Zuiani (1988).

\subsubsection{Sobre a estrutura da oração: posição de advérbios e quantificadores}

Quando o assunto é a estrutura da oração e o movimento do verbo, a comparação com línguas que movimentam ou não o verbo é inevitável. Como vimos acima, na seção 3, a posição dos advérbios e quantificadores tem sido usada como diagnóstico da posição do verbo na sentença. Vários estudos abordam esse tema no PB, numa abordagem comparativa, dentre eles: Galves (1990); Vitral (1992); Kato \& Nascimento (1996) e Figueiredo da Silva (1996). O interesse do tópico reside no fato de que o PB apresenta mais posições do que o inglês e o francês para posicionar os advérbios e os quantificadores flutuantes. Análises alternativas, com diferentes formas de implodir o núcleo flexão, são apresentadas.

No domínio da complementação por dois objetos,temos ainda os estudos de Scher (1996, 1997) e os de de Salles (1996a, 1996b, 1997) que comparam o português e o inglês.

Entre os estudos comparativos sobre a estrutura interna dos DPs temos os de Lobato (1989b e c), que comparam o PB com o francês. Outro estudo de Lobato (1993) estuda a colocação dos adjetivos do inglês e do português.

Na sub-área da morfologia de caso, temos Duarte (1987) sobre as passivas no português e no inglês; um estudo comparativo de Groppi (1997) sobre pronomes no PB e no espanhol do Uruguai; e uma tese de mestrado, de Luize (1997), sobre o PB e o PE açoreano falado em Santa Catarina. Sobre clíticos, temos Galves (1994), comparando o PB com o PE.

\subsection{Estudos diacrônicos}

No Brasil, o estudo da gramática na perspectiva diacrônica levantou interesse no período, em vista das enormes controvérsias sobre a existência ou não de um idioma brasileiro. Vários pontos dessa controvérsia podem ser recuperados em Tarallo (1993), para quem só um estudo rigoroso da língua, em 
seus aspectos estruturais, pode responder lingüisticamente se temos ou não uma nova gramática. Contudo, uma vez que a visão paramétrica só faz previsões sobre propriedades de construções gramaticais, ela não entra na discussão sócio-lingüística sobre identidade lingüística. $O$ francês antigo tinha propriedades diferentes do francês moderno, como se pode ver no estudo clássico de Adams (1987) e de Roberts (1993a), que alegam ter havido aí uma mudança paramétrica. Continua-se a assumir, contudo, que se trata da mesma língua externamente definida, embora internamente se trate de gramáticas distintas. O trabalho de Vilanova (1989) também estuda mudanças na ordem do francês antigo.

Alguns estudos diacrônicos vão até o latim, como é o caso do estudo de Lemle(1987) sobre a ordem no latim e em Camões. Em outro trabalho, Oliveira (1992) estuda o aparecimento do artigo definido no latim vulgar português.

Os estudos do português arcaico que aqui relatamos, embora escritos na visão da TPP, tiveram o sólido suporte de Mattos e Silva, na seleção e leitura dos textos. São eles os trabalhos de Ribeiro (1993, 1995, 1996b), principalmente sobre a ordem dos constituintes; e o de Augusto \& Guimarães (1996), sobre o sujeito na Carta de Caminha. Parecem ter sido exatamente as mesmas propriedades do francês antigo que se perderam no português, conforme diz Roberts (1993b), embora em período de tempo muito maior.

Os demais estudos tomam principalmente os dados do clássico para o presente.

Continuando o tema da ordem dos constituintes temos os trabalhos de Torres Morais (1993, 1995, 1997), para as declarativas, e os de Duarte (1992) e Lopes Rossi $(1993,1996)$,para as interrogativas. Na pesquisa dessas autoras, observa-se a perda das propriedades V2. Torres Morais, em seus trabalhos, aborda a posição dos clíticos, tópico que é amplamente investigado em outros trabalhos. Outro trabalho da autora é o que aborda a história da construção de topicalização (Torres Morais 1996). Lopes Rossi verifica não só a perda do movimento do verbo, mas do próprio pronome interrogativo-Q. Seu trabalho faz ainda uma análise das interrogativas com o expletivo "é que", derivandoas de orações clivadas. Discutindo esse trabalho e o de Kato \& Raposo (1996), que deriva a forma "O que que aconteceu" de "O que é que aconteceu", Mioto \& Figueiredo Silva (1995) apresentam uma crítica a essa análise.

Andrade Berlinck (1995) estuda a perda da ordem VS nos vários contextos 
(V1, V2, V3), já mais próximo do presente, e confirma a hipótese de Tarallo \& Kato (1989) de que os inacusativos são o domínio de resistência da mudança.

A seguir, temos os trabalhos sobre clíticos. Um dos primeiros trabalhos a mostrar a perda dos clíticos é o de Albuquerque (1982), que estuda o caso do dialeto mineiro. Esse fenômeno é observado como um fato mais geral dos clíticos no PB por Pagotto (1992) e como um fato mais específico do clítico de terceira pessoa por Cyrino (1994). No primeiro se estuda mais a fundo a perda do movimento do clítico e no segundo a forma como o objeto nulo foi ampliando o seu domínio. Nunes (1993) dá uma interpretação fonológica da perda do clítico. Esse autor é também conhecido por seus trabalhos sobre o "famigerado se" (Nunes, 1990, 1995). Um deles mostra a perda da passiva com se em favor das construções com o se impessoal e o outro estuda a perda do anafórico se. Há ainda o estudo de Britto (1997b) sobre os clíticos nos séculos XVIII a XIX. Trabalhos teóricos de interpretação dos fatos diacrônicos do clítico no português são os de Galves, como, por exemplo, Galves (1996).

Os estudos de Duarte (1993 e 1995) descobrem a perda diacrônica e em tempo real do sujeito nulo referencial no PB, atribuindo essa mudança à redução do paradigma de concordância. Negrão \& Müller (1996) contestam a tese da mudança defendida por Duarte, trabalhando também com os pronomes possessivos e nulos. O trabalho de Cyrino, Duarte e Kato (1996) relaciona a perda do sujeito referencial nulo do PB com o aumento do objeto referencial nulo, mostrando que as duas mudanças obedecem a um mesmo critério de lexicalização: a hierarquia de referencialidade. Tomando os estudos de Duarte (ops. cits.) para sujeito nulo e o de Cyrino (op. cit.) para objeto nulo, Oliveira (1995) analisa as pro-formas assertivas (respostas curtas), que no PB podem aparecer expressas por um núcleo verbal, conforme línguas que podem ter esses dois argumentos omissos, constatando que a cópula, em sua forma invariante É, vem substituindo os outros verbos.

No domínio dos sintagmas nominais, temos o estudo de Cerqueira (1993) sobre a mudança no paradigma dos possessivos. Há também o artigo de Kato (1993c), que propõe uma análise nova para as relativas resumptivas e cortadoras, derivando-as de extração da posição de deslocamento. Um outro estudo é o de Carvalho (1992) sobre a diacronia do verbo ser.

O trabalho de lingüística histórica de Almeida (1985) faz um estudo interessante acerca das classes de palavras, discutindo as oscilações encontradas em sua classificação nos compêndios gramaticais. Este estudo 
sugere que tais oscilações não parecem ser um fenômeno acidental, podendo ser o fato atribuído à reanálise de tais categorias.

\subsection{Estudos sobre línguas indígenas brasileiras}

Os estudos indígenas na linha da TPP iniciaram-se com a tese de doutorado de Daniel Everett (1983).

É surpreendente o interesse que a teoria da TPP despertou nos estudiosos das línguas indígenas, principalmente para os pesquisadores do Museu Nacional do Rio de Janeiro, tradicionalmente conhecido pelas suas pesquisas sobre as línguas e a cultura de nossos índios.

O grupo desenvolve presentemente um estudo comparativo da sintaxe e morfologia das línguas Kuikuro, Guarani, Karajá e Tikuna, no que diz respeito à estrutura da cláusula e à linearização em sua ordem SOV, já na visão minimalista de Kayne (1994) e Chomsky (1993).

Cada um dos autores, especialista em alguma dessas línguas, ou mais de uma, conduz, além disso, um estudo aprofundado da sintaxe e morfologia de sua língua-objeto. Assim, temos os trabalhos de Maia 1997a, b e c) e Maia $(1998,1999)$ sobre a estrutura clausal, o movimento-wh e a dêixis espacial e empática do Karajá; os de Franchetto $(1990,1994,1996)$ sobre a ergatividade do Kuikuro; os de Facó Soares (1989) sobre ordem, caso e movimento no Tikuna; os de Leite $(1991,1994)$ sobre a causatividade, a nãoconfiguracionalidade, atividade/ergatividade e a incorporação nominal no Tapirapé; e finalmente os de Vieira (1989, 1995a e b, 1997 a, b e c) sobre a língua Assurini, em seus aspectos não-configuracionais, quantificacionais e de marcação de caso. Há ainda vários trabalhos em co-autoria de Leite \& Vieira (1990, 1995 e 1996), com conteúdo comparativo.

Em outras universidades, verifica-se também um trabalho com línguas indígenas na linha da TPP. É o caso de Pereira (1992), que trabalhou com o Maxacali; o de Lovato do Nascimento (1995) sobre o Kaingang; os de Aguiar (1988, 1994), sobre o Katukina; e o de Pires (1992) sobre a língua Jeromiti.

Dois trabalhos estudam a categorização das palavras em línguas indígenas para a função de expressão de atributo. São eles os de Viana (1995) e o de Oliveira (1995) sobre as línguas Karajá e Ibibo, respectivamente. 


\subsection{Estudos sobre outras línguas}

Embora sejam poucos os trabalhos sobre outra língua, diferente do PB ou de uma língua indígena, tais trabalhos são importantes do ponto de vista teórico e também descritivo.

Os primeiros são os de Ilari \& Franchi (1985) e Franchi \& Ilari (1986) sobre clíticos e inversão no bielês, parte de um projeto maior sobre esse dialeto italiano. O segundo é o de Duarte (1994) sobre o fenômeno das preposições desacompanhadas do inglês e o terceiro, da mesma autora (Duarte, 1990), sobre reanálise. O próximo é um artigo do lituano, de Nunes (1994a) sobre a concordância no particípio, já na ótica Minimalista. Outro trabalho, de mestrado, que trata de concordância é o de Schlachter (1996) que trabalha com o dialeto alemão renano-palatino, também dentro do Minimalismo. Há ainda outro trabalho de mestrado, de Figueiredo Silva (1988), sobre clíticos no galego.

Constam também duas teses de mestrado, uma sobre a ordem no alemão (Weichel, 1997) e outra sobre a sintaxe histórica do francês (Vilanova, 1989).

\subsection{Estudos nas interfaces}

Com as mudanças operadas a partir do Minimalismo, os níveis de Forma Lógica (FL) e de Forma Fonética (FF) passam a ser os únicos níveis conceitualmente necessários. Embora alguns dos trabalhos citados não trabalhem ainda sob essa ótica, já os classificaremos como trabalhos nas interfaces devido à sua natureza. Considerareremos como relevantes no nível de FL os trabalhos que dizem respeito a escopo como é o caso da negação e de quantificadores. Quanto a trabalhos na interface sintaxe-fonologia, incluiremos aqui os trabalhos que analisam algum fenômeno do ponto de vista sintático e fonológico ou prosódico.

Dos trabalhos que têm a ver com a interface FL, valem menção os trabalhos de Mioto (1992, 1997a e 1997b), que analisam a estrutura da negação. Sobre quantificadores, um trabalho exaustivo e profundo é o de Negrão (1997b) usando a teoria de múltiplos núcleos funcionais para os vários tipos de expressão quantificada.

Dos trabalhos que têm a ver com a FF, vale menção aqui o trabalho de Galves \& Abaurre (1996) sobre os clíticos no PB contemporâneo; o de Callou et alii (1993) sobre a sintaxe e a prosódia de sentenças com topicalização e com 
deslocamento à esquerda; o de Leite et alii (1996) sobre a prosódia de construções com tópicos e adjuntos; e o de Kato (1996b) sobre a correlação ótima entre traços fonológicos e traços semânticos na mudança e aquisição da língua. Nessa interface situa-se também o projeto interdisciplinar "Padrões prosódicos, fixação de parâmetros e mudança gramatical", coordenado por Antônio e Charlotte Galves, do qual um dos trabalhos em circulação é Galves \& Galves (1995), que propõe uma modelagem matemática da relação da prosódia com a sintaxe na mudança da colocação de clíticos no português europeu.

Um trabalho de reflexão teórica sobre a sintaxe e a prosódia na perspectiva Minimalista é o de Guimarães (1997b).

III. Terceira parte: os anos de 1998 e 1999

Nesta seção alistamos os últimos títulos publicados que nos chegaram às mãos depois do artigo pronto, razão por que os trabalhos aparecem apenas listados.

\section{Estrutura do português brasileiro}

ABAURRE, M. B. and C. GALVES (1998) As diferenças rítmicas entre o português europeu e o português brasileiro: uma abordagem otimalista e minimalista. D.E.L.T.A 14: (2): 377-403.

ABREU, S. P. (1998) A negação sentencial: da teoria de princípios e parâmetros para o programa minimalista: uma investigação através do Português Brasileiro. Tese de Doutorado. PUC-RGS.

CASSANDRO, M.; P. COLLET; A. GALVES; and C. GALVES (1999) A Statistical-Physics approach to language acquisition and language change. Physica A 263: 427-437.

CHAVES, T. R. A. P. (1999) Construções participiais do português do Brasil. USP: Dissertação de Mestrado.

CYRINO, S. M. L. (1998) O objeto indireto nulo no português brasileiro. Signum 1: 35-54.

(1999) A categoria "INFL" no Português Brasileiro. Estudos Lingüísticos XXVIII: 449-454.

FILETTI, E. (1999) Ofenômeno dos objetos implícitos nos verbos no português do Brasil. Dissertação de Mestrado, UFMG.

FRANCHI, C.; E. V. NEGRÃO; E. S. VIOTTI (1998) Sobre a Gramática das Orações Impessoais com Ter/Haver. Revista D.E.L.T.A. 14, N. ${ }^{\circ}$ Esp.: 113-140. 
KATO, M. A. (1999) Construções de deslocamento à esquerda e o parâmetro do sujeito nulo. Atas do Congresso Internacional organizado por motivo dos vinte anos do português no ensino superior. Universidade Eotvos Lorand, Budapest: 207-223.

(1999) Strong and weak pronominals in the null subject parameter. PROBUS 11 (1): 1-38.

LOBATO, L. (1999) Sobre a forma do particípio do português e o estatuto dos traços formais. D.E.L.T.A. 15 (1): 113-140.

MENUZZI, S. M. (1999) Binding Theory and Pronominal Anaphora in Brazilian Portuguese. Ph.D. Dissertation. University of Leiden.

MIOTO, C. (1998) Aspectos da sintaxe da negação. Estudos Lingüísticos XXVII: 745-748.

(1998) Tipos de negação. Cadernos de Estudos Lingüísticos 34: 103 117.

NAVES, R. R. (1998) Aspectos sintáticos e semânticos das estruturas com verbos psicológicos. Dissertação de Mestrado. Brasília, UnB.

NEGRÃO, E. V. (1999) O Português Brasileiro: uma língua voltada para o discurso. USP: Tese de Livre-docência.

NICOLAU, E. M. D. (1998) Sobre a Caracterização do Sistema Flexional do Português Brasileiro. Gonçalves, G. \& G. Ravetti (eds.) Lugares Críticos. Belo Horizonte, MG, Orobó Edições: 19-55

RIBEIRO, I. (1998) O verbo: suas representações temáticas e sintáticas. SITIENTIBUS 8. UEFS: 83-91.

RODRIGUES, C. (1998) Aspectos sintáticos e semânticos da construção média: um estudo comparativo. Dissertação de Mestrado. Brasília, DF, UnB.

SALLES, H. M. M. L. (1999) Construções de Objeto Duplo em Português. Estudos Lingüísticos 28.

SANTOS, C. B. L. (1998) Algumas questões sobre a construção existencial e sua análise face a dados do português do Brasil. Dissertação de Mestrado. Brasília, DF, UnB.

VIOTTI, E. C. (1999) A Sintaxe das Sentenças Existenciais do Português do Brasil. São Paulo, SP, USP: Tese de Doutorado.

2. Estudos diacrônicos do português

CYRINO, S. M. L. (1998) Um plano para a sintaxe diacrônica do português brasileiro". In: A. T. Castilho (org.) Para a história do português brasileiro. Vol. I: Primeiras idéias. São Paulo, SP, Humanitas: 89-99. 
DUARTE, M. E. L. (1998) Left-Dislocated Subjects and Parametric Change in Brazilian Portuguese. Proceedings of the 16th International Congress of Linguists. (Paris, França) Cd-Rom, Session Syntax.

(1999) A Sociolingüística Paramétrica: Perspectivas. In: Hora, D. da \& E. Christiano (orgs.) Estudos Lingüísticos: realidade brasileira. João Pessoa: Idéia: 107-114.

FOLTRAN, M. J. G. D. As construções de Predicação Secundária no Português do Brasil. Aspectos Sintáticos e Semânticos. São Paulo, SP, USP: Tese de Doutorado.

RIBEIRO, I. (1998) A mudança sintática do PB é mudança em relação a que gramática? Para a história do português brasileiro. Vol. 1: Primeiras idéias. São Paulo: Humanitas Publicações / FFLCH/USP: 101-119.

(1998) Diferenças sintáticas entre o galego e o português dos séculos XIII e XIV. Atas do Simpósio de Língua e Imigração Galegas na América Latina: $65-86$.

RODRIGUES, G. F. S. (1998) Reestruturação nas Mini-orações. Dissertação de Mestrado, UFMG.

TORRES MORAIS, M. A. (1998) Para uma Abordagem Diacrônica do Português Brasileiro". In: CASTILHO, A. (org.) Para a História do Português Brasileiro. Vol I. Primeiras Idéias. Ed. Humanitas. FAPESP. VITRAL, L. (1999) A Negação: Teoria da Checagem e Mudança Lingüística. D.E.L.T.A. 15 (1): 57-84.

\section{Línguas Indígenas}

MAIA, M. et alii (1998) Comparação de Aspectos da Gramática em Línguas Indígenas Brasileiras. D.E.L.T.A. 14 (2): 349-375.

(1999) A Estrutura da Oração em Línguas Indígenas Brasileiras. D.E.L.T.A. 15 (1): 01-26.

SÂNDALO, F. (1997) A Grammar of Kadiwéu with special reference to the Polysynthesis Parameter. MIT Occasional Papers in Linguistics 11. 163 páginas.

(1999) Categorical Projections and Phrase Structure in Kadiwéu. In: Leora Bar-el, Rose-Marie Déchaine \& Charlotte Reinholtz (orgs.) Papers from the Workshop on Structure \& Constituency in Native American Languages. MIT Occasional Papers in Linguistics 17: 149-164.

(1999) Ergatividade Cindida em Kadiwéu e o Morfema Relacional. III Círculo de Estudos Lingüísticos do Sul, Porto Alegre, 18-21 de agosto. 
CYRINO, S. M. L. (1998) Sobre o componente morfológico e a forma da gramática. Estudos Lingüísticos XXVI(GEL), p. 586-591. (1998) Sobre a forma da Gramática. Boletim do CCH 35: 73-90, 1998.

FRANCHI, C.; E. V.NEGRÃO \& A. L. MÜLLER (1998) Um Exemplo de Análise e Argumentação. In: Sintaxe - Revista da ANPOLL 5: 37-63.

MIOTO, C. (1998) Preposições: núcleos funcionais ou lexicais? In: L. Cabral, L. Grimm \& E. Gorski (eds.) Lingüística e Ensino. Florianópolis, Insular: 165-179.

NUNES, J. (1998) Some Notes on Feature Mismatch. Cadernos de Estudos Lingüísticos 34: 33-40.

NUNES, J. (1998) The Copy Theory of Movement and Linearization of Chains in the Minimalist Program: Summary by the Author. GLOT International 8 (3): 16-17.

(1998) Bare X'-Theory and Structures Formed by Movement. Linguistic Inquiry 29 (1): 160-168.

(1999) Some Notes on Procrastinate and Other Economy Matters. D.E.L.T.A. 15 (1): 27-55.

VITRAL, L. (1999) A Negação: Teoria de Checagem e Mudança Lingüística. D.E.L.T.A. 15 (1): 57-84.

IV. Quarta Parte: Considerações finais

Uma olhada nos dados desta retrospectiva mostra que, de uma década de setenta tímida, entramos com toda força na década de oitenta e noventa.

A quantidade de professores visitantes dos Estados Unidos e Europa mostra que o país se abre para fora, não só para ouvir, mas também para ser ouvido. A importância do contingente formado no exterior está na ponte que eles estabelecem entre o centro onde fizeram seu doutorado e a instituição à qual eles se filiam.

O grupo de gerativa é hoje um grupo respeitado, não só pelo rigor formal de seus trabalhos estritamente gerativistas, mas pelo que ele tem conseguido produzir no campo empírico, seja em forma de diacronia, seja em forma de gramática da fala, seja na descrição de línguas indígenas. Isso para não falar das contribuições na área da psicolingüística.

Assim, esta retrospectiva mostrou que, enquanto a sintaxe se torna cada vez menor, "minimalista", o número de pesquisadores nessa linha aumenta em 
tamanho e expressão.

REFERÊNCIAS BIBLIOGRÁFICAS

ADAMS, M. (1987) Old French, Null Subjects and Verb Second Phenomena. Ph.D. Dissertation. UCLA.

AGUIAR, M. S. (1988) Elementos de Descrição Sintática para uma Gramática do Katukina. Dissertação de Mestrado. UNICAMP; (1994) Análise Descritiva e Teórica de Alguns Aspectos da Língua Katukina Pano. Tese de Doutorado. UNICAMP.

ALBUQUERQUE, A. C. R. C. (1982) A Perda dos Clíticos num Dialeto Mineiro. Dissertação de Mestrado. UFRJ.

ALKMIN, T. M. (1975) A classe difícil de predicados adjetivais do português. Dissertação de Mestrado. UNICAMP.

ALMEIDA, L. Q. (1977) Os reflexivos em português. Dissertação de Mestrado. UnB.

ALMEIDA, M. L. L. (1985) Preposição, Advérbio e Conjunção: um estudo de reanálise. Dissertação de Mestrado. UFRJ.

ALVARENGA, D. (1981) Interrogativas indiretas no português. Dissertação de Mestrado. UFMG.

ALVES, M. C. M. (1975) A redução anafórica. Dissertação de Mestrado. PUC-Campinas.

ANDRADE BERLINCK, R. (1995) La Position du sujet en Portugais. Tese de Doutorado. Katholieke Un. Leuven/UNICAMP.

ARRAIS, T. C. (1981) Predicação com verbos denominais em português. Anais do VEncontro Nacional de Lingüística. Rio de Janeiro, PUC-RJ.

ARRUDA, V. M. B. (1978) As passivas de estado e de mudança de estado em português contemporâneo. Dissertação de Mestrado. UnB.

ASSUNÇÃO, L. (1993) As Estruturas de Objeto Nulo sob a Perspectiva da Teoria de Princípios e Parâmetros. Dissertação de Mestrado. UFMG. AUGUSTO, M. R. A. (1994) Fatores Envolvidos na Extração dos Adjuntos$Q$. Dissertação de Mestrado. UNICAMP. \& M. GUIMARÃES (1996) O sujeito. In: Mattos e Silva, R.V. (org.)

AZEVEDO, M. G. C. M. (1977) Sobre o verbo "começar" em português. Dissertação de Mestrado. UFRJ.

AZEVEDO, M. M. (1973) On passive sentences in English and Portuguese. Ph.D. Dissertation, Cornell University.

BARBARA, L. (1975) A Sintaxe do Modo Verbal. Tese original de 1971, São Paulo, SP, Ática.

BARROS, A. R. M. P. (1977) Aspectos da complementação de uma classe de 
verbos de percepção. Dissertação de Mestrado. Unicamp.

BERG, M. B. (1996) A Natureza Categorial da Preposição. Dissertação de Mestrado. UFMG.

BERTHIER, L. O. (1974) Dar, fazer, ter, tomar, ser e estar: comportamento sintático-semântico de uma classe de verbos. Dissertação de Mestrado. UFRJ.

BISOL, L. (1972) Predicados complexos do português. Dissertação de Mestrado. UFRJ.

BITTENCOURT, V. (1979) A Posposição de Sujeito em Português. Dissertação de Mestrado, UFMG.

BOFF, A. (1991) A Posição dos Adjetivos no interior dos Sintagmas Nominais. Dissertação de Mestrado. UNICAMP.

BOTELHO PEREIRA, M. A. (1984) Gênero e Número em Português: um estudo da relação forma e sentido. Tese de Doutorado. UFRJ.

BOTELHO PEREIRA, M. A. \& C. N. RONCARATI (1993) O caso do sujeito em orações infinitivas introduzidas por 'para' no português do Rio. D.E.L.T.A. 9 (1): 15-30.

BRANCO, M. C. (1979) O particípio passado como pré-modificador em inglês. Dissertação de Mestrado. PUC-SP.

BRANDON, F. (1976) Quantificação e negação em português. Revista Brasileira de Lingüística 3 (1). Ano II: 92-108.

BRENNER, T. M. (1977) O modelo de Klima e a dupla negação em português. Dissertação de Mestrado. UFRGS.

BRISOLLA, S. S. (1980) As construções SN-Adj-SPrep em português: um problema difícil de resolver. Dissertação de Mestrado. UnB.

BRITTO, H. S. (1994) Reduzidas de Gerúndio: teoria do caso e inversão verbo/sujeito. Dissertação de Mestrado. UNICAMP.

(1996) Sentenças com tópico no PE, PB e Inglês: um estudo acerca das construções de deslocamento. Comunicação apresentada no XI Encontro Nacional da ANPOLL. Junho de 1996, João Pessoa.

(1997a) Canonical and inverted copular sentences and restriction to the presence of the subject. Comunicação apresentada no VII Colóquio de Gramática Gerativa. Abril de 1997. Oviedo, Espanha.

(1997b) Clitic placement in the history of European Portuguese between the XVIIIth and XIXth centuries. Comunicação apresentada em The XIII International Conference on Historical Linguistics. Agosto, 1997. Düsseldorf.

CALLOU, D.; J. MORAES; Y. LEITE; M. A. KATO; C. T. de OLIVEIRA E COSTA; M. ORSINI \& V. RODRIGUES (1993) Topicalização e deslocamento à esquerda: sintaxe e prosódia. In: Castilho, A. (org.) 
(1993) (op. cit. n. ${ }^{\circ}$ 32).

CÂMARA JR., J. M. (1967) O estruturalismo lingüístico. Tempo Brasileiro, 15-16: 5-44.

CAMPOS, E. (1977) Pronomes possessivos em português. Dissertação de Mestrado. UnB.

CANÇADO, M. (1995a) Relações Estruturais e Semânticas dos Verbos Psicológicos. Tese de Doutorado. UNICAMP.

(1995b) A teoria da proeminência de Grimshaw e os psico-verbos do português brasileiro. D.E.L.T.A. 11 (2): 279-299.

CARDOSO, S. H. B. (1976) O processo de relativização em diferentes registros do português. Dissertação de Mestrado. PUC-Campinas.

CARVALHO, M. B. (1975) Regras de 'foregrounding': evidência do português. Dissertação de Mestrado. UNICAMP.

CARVALHO, O. L. S. (1992) O Verbo Ser na diacronia do português: 3 séculos em estudo. Dissertação de Mestrado. UnB.

CASTILHO, A. (org.) (1990) Gramática do Português Falado, Vol.. I: A Ordem. Campinas, SP: Editora da UNICAMP, São Paulo: FAPESP.

CASTRO, @. (1997) A Categoria Vazia no Sintagma Determinante: licenciamento sintático e implicação semântica. Dissertação de Mestrado. UFRJ.

CAVALCANTE, M. P. (1972) Um estudo sobre a formação de 'tags' no português. Dissertação de Mestrado. PUC-SP.

CERQUEIRA, V. (1993) A forma genitiva 'dele' e a categoria de concordância (AGR) no português brasileiro. In: Roberts, I. \& M. A. Kato (orgs.): 129-162.

(1995) A Sintaxe do Possessivo no Português Brasileiro. Tese de Doutorado. UNICAMP.

(1984) O presente simples e progressivo do inglês e o presente do indicativo e progressivo do português: um estudo comparativo. Dissertação de Mestrado. PUC-SP.

CHAGAS DE SOUZA, P. (1997) As causativas implícitas do Português do Brasil. Anais do XXVI Seminário do GEL: 195-201.

CHAVES, T. R. A. P. (1997) A sintaxe das construções de voz passiva no Português do Brasil. Seminários de Lingüística, FFLCH-USP.

CHOMSKY, N. (1995) The Minimalist Program. Cambridge: Mass. MIT Press.

(1993) A minimalist program for linguistic theory. In: K. Hale \& S. J. Keyser (eds.) The View from Building 20, Cambridge: Mass. MIT Press.

COHEN, M. A. A. (1982) Orações restritivas em português. Dissertação de 
Mestrado. UFMG.

CORÔA, M. L. M. S. (1983) O tempo nos verbos do português: Uma introdução à sua interpretação semântica. Dissertação de Mestrado. UnB.

CUNHA, M. A. F. (1978) Sobre os tratamentos transformacionalista e léxicointerpretativo das construções passivas em português. Dissertação de Mestrado. UnB.

CYRINO, S. M. L. (1993) Observações sobre a mudança diacrônica no português do Brasil: objeto nulo e clíticos. In: Roberts, I. \& M. A. Kato (orgs.) (op. cit. n. $\left.{ }^{\circ} 45\right)$.

(1994) O objeto nulo no Português do Brasil: um estudo sintáticodiacrônico. Campinas, SP, UNICAMP, Ph.D. Dissertation.

(1996) O objeto nulo do português brasileiro. D.E.L.T.A. 12 (2): 221238.

(1997a) Objeto indireto nulo e 'dative shift'. Anais do XXVI Seminário do GEL: 466-471.

(1997b) Objetos nulos e elipse de VP. Anais do I Encontro do CELSUL: 595-603.

CYRINO, S. M. L; M. E. L. DUARTE \& M. A. KATO (1996) Visible subjects and invisible clitics in Brazilian Portuguese. NWAVE XXV, Las Vegas. University of Nevada.

DE FILIPO, F. (1977) A supressão de constituinte coordenado em português. Dissertação de Mestrado. UFMG.

DECAT, M. B. N. (1978a) Sujar: um ou dois verbos. Ensaios de Lingüística 1: 9-19.

(1978b) Movimento de Sintagma Nominal Interrogado em português. Dissertação de Mestrado. UFMG.

(1980) Interrogativa múltipla: condições sobre o movimento do sintagma interrogado. Ensaios de Lingüística 3: 56-71.

Dillinger, M.; C. Galves, E. Pagotto \& V. Cerqueira (1996) Padrões de complementação na gramática do português falado. In: M. A. Kato (org.).

DILLINGER, M. \& M. Nascimento (1994) The role of the lexicon in the syntax/ semantics interface. Comunicação apresentada no I Encontro Internacional da ABRALIN, Salvador.

DUARTE, M.E. L. (1992) A perda da ordem V(erbo) S(ujeito) em interrogativas qu- no português do Brasil. D.E.L.T.A. 8 (Especial): 37-52.

(1993) Do pronome nulo ao pronome pleno: a trajetória do sujeito no português do Brasil. In: Roberts, I. \& M. A. Kato (orgs.): 107-128.

(1995) A Perda do Princípio "Evite Pronome" no Português Brasileiro. Tese de Doutorado. UNICAMP. 
(1997) O sujeito nulo no português europeu e no português brasileiro. Comunicação apresentada no XLV Seminário do GEL. Maio de 1997, UNICAMP.

DUARTE, Y. (1987) As Construções Passivas do Português e do Inglês: um estudo comparativo. Tese de Doutorado. PUC-SP.

(1990) A reanálise de $\mathrm{V}+\mathrm{P}$ nas passivas do inglês: uma proposta alternativa. Anais do IV Encontro Nacional da ANPOLL: 853-62. São Paulo.

(1993) A hipótese inacusativa e as evidências do português. D.E.L.T.A. 9 (1): 31-58.

(1994) As construções desacompanhadas no inglês. D.E.L.T.A. 10 (2): 409-420.

EVERETT, D. (1983) A Língua Pirahã e a Teoria da Sintaxe. Tese de Doutorado. UNICAMP.

FACÓ SOARES, M. (1989) Marcação de caso e atribuição de caso em Tikuna. Cadernos de Estudos Lingüísticos 18: 79-114.

FÁVERO, L. (1974) Complementação de predicado em português. Tese de Doutorado. PUC-SP.

(1982) O modo verbal da oração completiva. Revista Brasileira de Lingüística. São Paulo, SP, Global.

FIAD, R. S. (1975) Aspectos da negação. Dissertação de Mestrado. UNICAMP.

FIGUEIREDO SILVA, M. C. (1988) Clíticos no galego: uma descrição dentro do quadro da Regência e Vinculação. Dissertação de Mestrado. UNICAMP.

(1996) A Posição do Sujeito no Português Brasileiro. Campinas, Editora da UNICAMP.

(1997) Notas para um estudo sobre infinitivas em PB. Anais do I Encontro do CELSUL: 621-629.

FIGUEIREDO, A. B. (1975) Raising: deslocamento de sujeito na estrutura encaixada. Dissertação de Mestrado. PUC-Campinas.

FONTES, S. M. (1978) As construções comparativas do português e do inglês: um estudo contrástico e uma análise dos problemas de tradução. Dissertação de Mestrado. PUC-SP.

FRANCHETTI, S. (1997a) Algumas considerações sobre o uso de mesmo e próprio no PB. Seminários em Teoria Gramatical. FFLCH-USP.

(1997b) Ele mesmo e himself: formas análogas ou não? Seminários em Teoria Gramatical, FFLCH-USP.

FRANCHETTO, B. (1990) A ergatividade Kuikuro (Karibe): algumas propostas de análise. Cadernos de Estudos Lingüísticos 18: 57-78. 
(1994) A ergatividade em Kuyikuro: quadro geral, hipóteses explicativas e uma visão comparativa. Revista Latino-Americana de Estudos Etnolingüísticos, Vol. VII: 7-16.

(1996) As línguas ergativas e a teoria da gramática. Salvador, Anais do I Encontro Internacional da ABRALIN: 220-226.

FRANCHI, C. (1997) Teoria da Adjunção: predicação e relações temáticas. Seminários de Teoria Gramatical 5. FFLCH-USP.

FRANCHI, C. \& R. ILARI (1986) Clíticos nominativos e inversão do sujeito em bielês. D.E.L.T.A. 2 (1): 77-104.

FREITAS, J. D. F. (1991) As predicações não-verbais no Português do Brasil: uma abordagem gerativa. Dissertação de Mestrado, UFMG.

GALVES, A. \& C. GALVES (1995) A case study of prosodic driven language change. Comunicação apresentada no 3rd Workshop on Statistical Physics, Pattern Recognition and Grammar Selection. Instituto de Estudos Avançados-USP, São Sebastião.

GALVES, C. (1984) Pronomes e categorias vazias em Português do Brasil. Cadernos de Estudos Lingüísticos 7: 107-136.

(1986a) luga-(se) casas: um problema da sintaxe portuguesa na teoria da regência e da vinculação. Preedição 2. Campinas, UNICAMP.

(1986b) A interpretação 'reflexiva' do pronome no português do Brasil. D.E.L.T.A. 2 (2): 249-264.

(1987) A sintaxe do português brasileiro. Ensaios de Lingüística 13: 31-50.

(1989) L'objet null et la structure de la proposition en portugais du Brésil. Revue de Langues Romanes 93 (2): 305-336.

(1990) V-movement, levels of representation and the structure of S. In: Chao, W. \& G. Horrocks (orgs.) Levels of Representation. Dordrecht: Foris.

(1992) Inflected infinitives and AGR licensing. Campinas, UNICAMP, ms.

(1993) O enfraquecimento da concordância no PB. In: Roberts, I. \& M. A. Kato (orgs.): 387-408.

(1994) A colocação dos clíticos no Português Europeu. Anais da ANPOLL VII (2): 889-902.

(1996) Clitic placement and parametric change in Portuguese. In: C. Parodi et alii (orgs.).

(1997) S ubjects, weak pronouns and AGR: the case of Brazilian Portuguese. Workshop de Teoria Gramatical: problemas nos níveis de interface. Agosto de 1997. UNICAMP/USC.

GALVES, C. \& M. B. M. ABAURRE (1996) Os clíticos no Português Brasileiro: 
elementos para uma abordagem sintático-fonológica. In: Castilho, A. \& M. Basílio (orgs.) (1996) (op. cit. n. ${ }^{\circ} 138$ ).

GAMARSKY, L. (1974) Ocorrência de reflexivo nas construções incoativas. Dissertação de Mestrado. PUC-SP.

GOMES, M. L. (1975) O deslocamento como processo sintático e suas implicações sintáticas e semânticas. Dissertação de Mestrado. PUCCampinas.

GONÇALVES PINTO, R. (1991) O Predicado verbo-nominal: uma abordagem gerativa. Dissertação de Mestrado. UnB.

GROPPI, M. (1997) Pronomes Pessoais no Português do Brasil e no Espanhol do Uruguai. Tese de Doutorado. USP.

GUIMARÃES, M. (1997a) A representação sintática dos artigos e dos demonstrativos numa perspectiva minimalista. Anais do XXVI Seminário do GEL: 550-556.

(1997b) Unifying LCA and prosodic phrasing in the Minimalist program. Comunicação apresentada no Workshop de Teoria Gramatical: problemas nos níveis de interfaces. Agosto de 1997, Campinas, UNICAMP/USC.

HUANG, C. T. J. (1984) On the distribution and reference of the empty categories. Linguistic Inquiry 15: 531-574.

HUMBERTO, M. L. F. (1975) Uma análise transformacional do processo de concordância em português. Dissertação de Mestrado. PUC-Campinas.

IKEDA, S. (1977) A função do pronome se. Dissertação de Mestrado. PUCSP.

ILARI, R. \& C. FRANCHI (1985) Nominative clitics in biellese - morphological and distributional suovery. Cadernos de Estudos Lingüísticos 8: 135149.

ILARI, R. (org.) (1992) Gramática do Português Falado, Vol.. I: Níveis de Análise. Campinas, SP: Editora da UNICAMP, São Paulo: FAPESP.

JACKENDOFF, R. (1990) Semantic Structures. Cambridge, Mass. The MIT Press.

JORGE, L. T. L. (1986) Complementação do Nome: relações semânticas e estruturas sintáticas: uma proposta de revisão da análise tradicional. Dissertação de Mestrado. UnB.

KATO, M. A. (1974) A Semântica Gerativa e o Artigo Definido. Tese original de 1972. São Paulo, SP, Ática.

(1976a) A elisão do pronome sujeito em português e a hipótese do discurso direto de Kuno. Anais do I Encontro Nacional de Lingüística. Rio de Janeiro.

(1976b) Transitividade Verbal e decomposição lexical. Revista 
Brasileira de Lingüística. Petrópolis, Vozes 3 (1): 3-21.

(1977) Restrições gerais à regra de omissão do pronome sujeito em português. Anais do II Encontro Nacional de Lingüística. PUC-RJ.

(1981) Restrições à regra da elipse verbal. Ensaios de Lingüística 5: 93-101.

(1987) Inversão da ordem SV em interrogativas no português. D.E.L.T.A. 3 (2): 243-252.

(1989) Sujeito e tópico: duas categorias na sintaxe? Cadernos de Estudos Lingüísticos 17: 109-132.

(1992) Variação sintática e estilo. Cadernos de Estudos Lingüísticos 22: $127-139$.

(1993a) Word order change: the case of Brazilian Portuguese whquestions. Trabalho apresentado no The XIth International Congress on Historical Linguistics. Los Angeles: UCLA.

(1993b) The distribution of null and pronominal objects in Brazilian Portuguese. Linguistic Perspectives on the Romance Languages: Selected Papers from the XXI Linguistic Symposium on Romance Languages. Amsterdam, John Benjamins: 225-235.

(1993c) Recontando a estória das relativas. In: Roberts, I. \& M. A. Kato (orgs.): 223-261.

(1996a) Português brasileiro falado: aquisição em contexto de mudança lingüística. Actas do Congresso Internacional sobre o Português. Lisboa, Universidade de Lisboa: 211-237.

(1996b) The morpho-phonology of strong and weak pronouns and the pro-drop parameter. Comunicação apresentada no Seminário de Morfologia. Novembro de 1996. USC.

(1998) Tópicos como alçamento de predicados secundários. Cadernos de Estudos Lingüísticos, 34: 67-76.

(1999) Aquisição de linguagem numa abordagem gerativa. Letras de Hoje 34 (3), setembro de 1999: 17-26.

KATO, M. A.; M.L.BRAGA; V.R. CORREA;M. A.LOPES ROSSI\& N. SIKANSI (1996) Construções-Q na gramática do português falado. In: I. V. Koch (org.) Gramática do Português Falado, Vol. VI: Desenvolvimentos. Campinas, SP: Editora da UNICAMP, São Paulo: FAPESP: 303-368.

KATO, M. A. \& A. CASTILHO (1991) Advérbios como núcleos predicadores. D.E.L.T.A. 7 (1): 409-423.

KATO, M. A. \& M. do NASCIMENTO (1996) Preenchedores aspectuais e o fenômeno da flutuação dos quantificadores. In: A. Castilho \& M. Basílio (orgs.) (1996) Gramática do Português Falado, Vol. IV: Estudos Descritivos. Campinas, SP: Ed. da UNICAMP, São Paulo: FAPESP: 
245-272.

KATO, M. A.; M. do NASCIMENTO; E. NICOLAU; R. BERLINCK \& H. BRITTO (1996) Padrões de predicação na gramática do português falado. In: KATO, M. A. (org.) Gramática do Português Falado, Vol. V: Convergências. Campinas, SP, Ed. da UNICAMP, FAPESP: 201-274.

KATO, M. A. \& E. RAPOSO (1996) European and Brazilian Portuguese word order: questions, focus and topic constructions. In: C. Parodi, C. Quicoli, M. Saltarelli \& M. L. Zubizarreta (orgs.) (1996) Aspects of Romance Linguistics. Washington, Georgetown Univ. Press: 267-277.

KAYNE, R. (1994) The Antisymmetry of Syntax. Cambridge, Mass., The MIT Press.

KNEIPP, M. A. R. (1978) Uma proposta de análise para o morfema 'não' em português. Dissertação de Mestrado. UnB.

KURODA, S. Y. (1976) The concept of subject in grammar. In: M. Shibatani (org.) Syntax and Semantics: Japanese generative Grammar. New York, Academic Press: 1-16.

LEITE, Y. (1991) Não-configuracionalidade nas línguas da família Tupi-Guarani? Simpósio: Desenvolvimentos Recentes em Gramática Gerativa. Brasília. (1994) As construções causativas em tapirapé. In: Revista Interamericana de Estudos Etnolingüísticos 8: 73-86.

(1995) A incorporação nominal em tapirapé. Comunicação apresentada no X Congresso Internacional da ALFAL. Vera Cruz, México.

LEITE, Y.; D. CALLOU; J. MORAES; M. A. KATO; M. ORSINI; V. RODRIGUES \& E. COSTA (1996) Tópicos e Adjuntos. In: Castilho, A. \& M. Basílio (orgs.): 321-342.

LEITE, Y. \& M. D. VIEIRA (1990) Atividade e ergatividade nas línguas da família Tupi-Guarani: problemas de análise. Anais do V Encontro Nacional da ANPOLL: 247-255. Recife.

(1995) A incorporação nas línguas da família Tupi-Guarani: um processo sintático? Atas do X Encontro Nacional da ANPOLL: Caxambu.

(1996) A ordem livre em algumas línguas da família Tupi-Guarani: em busca de uma proposta de análise. Anais do I Encontro Internacional daABRALIN: 503-513.

LEMLE, M. (1967) O novo estruturalismo em lingüística: Chomsky. Tempo Brasileiro 15-16: 51-64.

(1978) Da maleabilidade da análise sintagmática. Revista Brasileira de Lingüística 5 (1): 89-121.

(1979) A ordem dos adjetivos no sintagma nominal em inglês e português: implicações para a teoria gramatical. Anais do III Encontro Nacional de Lingüística. PUC-RJ. 
(1985) Pronomes, anáforas, zero: observações sobre uma mudança lingüística. D.E.L.T.A. 1 (1/2): 121-124.

(1987) Movimento para posição não-argumental na poesia latina e na épica camoniana. Tese de Livre-docência. UFRJ.

(1984) Análise Sintática: teoria geral e descrição do português. São Paulo, SP, Ática.

LEMLE, M. \& A. NARO (1977) Sobre sintagmas nominais maximamente preenchidos (ms.).

LIER, C. A. O. D. (1977) As construções causativas e incoativas do inglês e do português. Dissertação de Mestrado. PUC-SP.

LOBATO, L. M. P. (1978) Existe mais de um verbo poder em português? Anais do III Encontro Nacional de Estudos de Lingüística e Literatura. Rio de Janeiro, RJ, Corujinha.

(1979) A favor da univocidade dos modais em português. Anais do III Encontro Nacional de Lingüística. PUCRJ: 250-274.

(1988a) Sintaxe Gerativa do Português: Da teoria padrão à teoria da regência e ligação. Belo Horizonte, Vigília.

(1988b) PCV, subjacência e CVs do Português. Comunicação apresentada no III Encontro Nacional da ANPOLL, Rio de Janeiro.

(1988c) Sobre a regra da anteposição do verbo no português do Brasil. D.E.L.T.A. 4 (1): 121-147.

(1989a) Estatuto sintático das categorias vazias em estruturas com adjetivos do tipo fácil em português. Anais do XI Encontro Nacional de Lingüística: @. PUC, RJ.

(1989b) Deslocamento dentro e para fora de SNs em português e em francês. Boletim da ABRALIN 10: 35-51.

(1989c) Sobre algumas diferenças entre os SNs do francês e do português. Comunicação apresentada no IV Encontro Nacional da ANPOLL.

(1993) Adjetivos: uma tipologia e interpretação semântica. Boletim da ANPOLL 14: 9-25.

(1994a) Como se chega à sintaxe a partir do léxico? Comunicação apresentada no IX Encontro Nacional da ANPOLL, Caxambu.

(1994b) A concordância nominal no português do Brasil à luz da teoria de Princípios e Parâmetros. D.E.L.T.A. 10 (Especial): 173-212.

LOPES ROSSI, M. A. (1993) Estudo diacrônico das interrogativas do português do Brasil. In: Roberts, I. \& M. A. Kato (orgs.): 307-342.

(1996) A Sintaxe Diacrônica das Interrogativas- $Q$ do Português. Tese de Doutorado. UNICAMP.

LOVATO DO NASCIMENTO, S. H. (1995) Aspectos Morfológicos e Sintáticos 
e Marcação de Caso na Língua Kaingang. Dissertação de Mestrado. UFSC.

LUIZE, T. B. (1997) Entre o Português Europeu e o Português Brasileiro: o falar açoriano de Florianópolis. Dissertação de Mestrado. UFSC.

LUZ, G. A. (1994) O Infinitivo Pessoal: uma análise do português contemporâneo. Dissertação de Mestrado. UNICAMP.

(1997) Personal infinitives in Romance languages. Comunicação apresentada no Workshop de Teoria Gramatical: problemas nos níveis de interfaces. Agosto de 1997. Campinas.

MACHADO, M. C. C. (1979) Subordinadas adverbiais em francês e português. Dissertação de Mestrado. UFRJ.

MADUREIRA, C. S. (1975) Alguns verbos aspectuais em português. Dissertação de Mestrado. UNICAMP.

MAIA, M. (1997a) Notes on Karaja clause structure. Comunicação apresentada no XVI Congrès International de Linguistes, Paris. (1997b) A sintaxe da dêixis espacial em Karaja. Trabalho apresentado na Mesa Redonda Perspectivas da Pesquisa em Línguas Indígenas Brasileiras. Encontro da ABRALIN, UFAL, Maceió. et alii (1997c) The syntax of wh-questions in Karaja, Kayapo (MacroJe) and Machineri (Arawaki). Comunicação apresentada no $49^{\circ}$ Congresso Internacional de Americanistas, Quito. et alii (1998) Comparação de Aspectos da Gramática em Línguas Indígenas Brasileiras. D.E.L.T.A. 14 (2): 349-375.

MAIA. et alii (1999) A Estrutura da Oração em Línguas Indígenas Brasileiras. D.E.L.T.A. 15 (1): 01-26.

MAIA, V. L. M. (1975) Interrogação e relativização em português. Dissertação de Mestrado. UNICAMP.

MARTIN, J. (1975) Concordância. Revista Brasileira de Lingüistica 2 (2). Ano I: 50-72.

MARTINS, E. J. (1976) Origem e função dos pronomes complemento de terceira pessoa. Letras de Hoje 26: 123-133.

MATOS, A. S. A. (1991) Construções com Verbos de Percepção no Português do Brasil: uma abordagem gerativa. Dissertação de Mestrado. UnB.

MENEZES, H. P. (1979) A regra do alçamento de sujeito em português. Dissertação de Mestrado. UFRJ.

(1989) As Construções Comparativas em Português: uma análise gerativa. Tese de Doutorado. UFRJ.

MENUZZI, S. (1994) Algumas observações acerca do movimento de verbos nas interrogativas-wh do português. Letras de Hoje 96: 85-109.

MIOTO, C. (1975) Estruturas que implicam a noção de experiência. 
Dissertação de Mestrado. PUC-Campinas.

(1989) Construções interrogativas: elementos para uma análise do português do Brasil. Cadernos de Estudos Lingüísticos 17: 39-64.

(1992 ) Negação Sentencial no Português Brasileiro e o Critério WH. Tese de Doutorado. UNICAMP.

(1994) A s interrogativas no português brasileiro e o critério-wh. Letras de Hoje 96: 19-33.

(1997a) Aspectos da sintaxe da negação. UFSC, ms.; (1997b) "Os itens negativos". UFSC, ms.

(1997b) Wh é que ${ }^{1}$ wh que. Anais do XXVI Seminário do GEL: 648654.

MIOTO, C. \& M. C. FIGUEIREDO SILVA (1995) WH QUE =WHÉ QUE? D.E.L.T.A. 11 (2): 301-311.

MIRANDA, Z. B. A. G. (1975) Aspectos do comportamento sintático dos modais dever e poder. Dissertação de Mestrado. UNICAMP.

MODESTO, M. (1995) As Construções Clivadas no PB: relações entre interpretação focal, movimento sintático e prosódia. Dissertação de Mestrado. USP.

(1996) Topics and focalized phrases in Brazilian Portuguese. Colloquium on Portuguese Linguistics. Dept of Spanish and Portuguese, UCSB.

MOLLICA, C. (1977) Estudo da cópia nas construções relativas em português. Dissertação de Mestrado. PUC-RJ.

MORAES, E. (1971) O infinitivo flexionado em português: uma análise transformacional. Dissertação de Mestrado. UFRJ.

MOREIRA DA SILVA, S. (1983) Études sur la Symétrie et l'Asymétrie SUJET/ OBJET dans le Portugais du Brésil. Tese de Doutorado. Un. Paris VIII. MOURÃO, E. (1996) Pronome Lexical na posição de sujeito de Sentenças Finitas do Português. Dissertação de Mestrado. UFMG.

MOUTELLA, E. M. (1995) O Gerúndio Oracional em Português. Dissertação de Mestrado, UnB.

MÜLlER, A. (1996) A Sintaxe e a Semântica dos Possessivos no Português do Brasil. Tese de Doutorado. UNICAMP.

NARO, A. J. (1976) Tendências Atuais da Lingüística e da Filologia no Brasil. Rio de Janeiro, RJ, Francisco Alves.

NASCIMENTO, M. (1978) Sobre a semântica da passiva. Dissertação de Mestrado. UFMG.

(1984) Sur la Postposition du Sujet dans le Portugais du Brésil. Tese de Doutorado. Un. Paris VIII.

NASCIMENTO, M. \& M. A. KATO (1995) O estatuto dos nominais pós- 
verbais dos verbos inacusativos. Revista de Estudos da Linguagem, Ano IV (3): 31-74.

NEGRÃO, E. V. (1986) Anaphora in Brazilian Portuguese Complement Structure. Ph.D. Thesis. University of Wisconsin.

(1989) 'PRO' e controle: problemas em algumas estruturas de complementação. Anais do IV Encontro Nacional da ANPOLL, Recife. (1992) Tem uma história que começa assim: peculiaridades de uma construção existencial. Caderno de Estudos Lingüísticos 22: 81-90.

(1997a) Asymmetries in the distribution of overt pronouns and empty categories in Brazilian Portuguese. In: Black, J. R. \& V. Motapanyane (orgs.) Clitics, Pronouns and Movement. Amsterdam: John Benjamins.

(1997b) The scopal properties of DPs in Brazilian Portuguese. Seminários em Teoria Gramatical. USP, ms.

NEGRÃO, E. V. \& A. L. MÜLLER (1990) Anáfora em algumas estruturas de complementação. Anais do XIX Seminário do GEL: 133-140.

(1996) As mudanças no sistema pronominal do Português Brasileiro: substituição ou especialização de formas? D.E.L.T.A. 12 (1): 125-152.

NICOLAU, E. (1995) As propriedades de sujeito nulo e de inversão no Português Brasileiro. Tese de Doutorado. UNICAMP.

(1997) O licenciamento do sujeito nulo: uma explicação nos moldes do Programa Minimalista. Comunicação apresentada no XLV Seminário do GEL, Campinas. UNICAMP.

NOVAES, C. V. (1996) Representação mental de Categorias Vazias: o caso do sujeito nulo no português do Brasil. Tese de Doutorado. UFRJ.

NUÑES COSTA, M. G. (1989) A questão da ergatividade do português do Brasil. Tese de Mestrado. UFRJ.

NUNES, G. M. (1997) A anteposição dos adjetivos ao nome dentro do SN. Anais do XXVI Seminário do GEL: 150-156.

NUNES, J. (1990) O Famigerado SE. Tese de Mestrado. UNICAMP. (1995) Ainda o famigerado SE. D.E.L.T.A. 11 (2): 201-254.

(1993) Direção de cliticização, objeto nulo e pronome tônico na posição de objeto em português brasileiro. In: Roberts, I. \& M. A. Kato (orgs.): 207-222.

(1994) Concordância de particípio em lituano. Letras de Hoje 96: 5984.

(1994) Nominative pronoun reduction in Brazilian Portuguese. University of Maryland, ms.

NUNES, J. \& E. RAPOSO (1997) Inflected infinitive in Portuguese: evidence against AGR. Comunicação apresentada no Workshop de Teoria Gramatical: problemas nos níveis de interface. Agosto de 1997. 
Campinas. UNICAMP/USC.

OLIVEIRA, A. M. C. O. (1996) Dos Advérbios. Dissertação de Mestrado. UNICAMP.

OLIVEIRA, M. (1992) A expansão do Sintagma Nominal no Latim Vulgar e no Latim Português. Dissertação de Mestrado. UNICAMP.

(1995) Respostas Assertivas e sua Variação nas Línguas Românicas. Tese de Doutorado. UNICAMP.

(1997) O preenchimento do sujeito no italiano e no português do Brasil. Comunicação apresentada no XLV Seminário do GEL. Maio de 1997, UNICAMP.

OLIVEIRA, M. A. (1975) A sintaxe do verbo "esquecer-se". Dissertação de Mestrado. UNICAMP.

(1978) Clitic Placement in Portuguese. Ensaios de Lingüística 1: 4479.

OLIVEIRA, M. S. D. (1995) A Expressão de Atributo na Língua Ibibo. Dissertação de Mestrado. UnB.

PAGOTTO, E. (1992) A Posição dos Clíticos em Português. Dissertação de Mestrado. UNICAMP; (1993) Clíticos, mudança e seleção natural. In: Roberts, I. \& M. A. Kato (orgs.) (op. cit. n. ${ }^{\circ} 45$ ).

(1993) Clíticos, mudança e seleção natural. In: Roberts \& Kato (orgs): 185-206.

PARISI, L. A. P. (1977) Aspectos da gramatica dos advérbios em -mente no Português do Brasil. Dissertação de Mestrado. UnB.

PARODI, C.; C. Quicoli; M. Saltarelli \& M. L. Zubizarreta (orgs.) (1996) Aspects of Romance Linguistics. Washington, Georgetown U. Press.

PAZINI, M. C. B. (1978) A posição do adjetivo na locução nominal em português. Revista Brasileira de Lingüística 5 (1), Ano IV: 27-52.

PEREIRA, D. G. (1992) Alguns Aspectos Gramaticais da Lingua Maxacali. Dissertação de Mestrado. UFMG.

PEREIRA, M. A. B. (1974) A oposição modal indicativo/subjuntivo em português. Dissertação de Mestrado. UFRJ.

(1978) Considerações sobre a complementação nominal em português. Revista Brasileira de Lingüística 5 (1). Ano IV: 57-78.

PEREIRA, S. M. C. (1979) Formas gerundiais em francês e português problemas de tradução e análise. Dissertação de Mestrado. UFMG.

PERINI, M. A. (1974) A grammar of Portuguese Infinitives. Ph.D. Dissertation. University of Texas.

(1977) Uma restrição global em português. Revista Brasileira de Lingüística 4 (2). Ano III: 3-16.

(1978) Sintaxe e semântica do futuro do subjuntivo. Ensaios de 
Lingüística 1: 20-43.

(1976) A Gramática gerativa: introdução ao estudo da sintaxe portuguesa. Belo Horizonte, MG, Vigília.

PIMENTA-BUENO, M. (1978) Aspects of Verbal Syntax in Brazilian Portuguese within the Framework of the Extended Standard Theory. Ph.D. Dissertation. Stanford University.

PIMENTA-BUENO, M. N. S. (1981a) Em prol da redefinição da noção de "sujeito de" - evidências do português. Anais do V Encontro Nacional de Lingüística. PUCRJ.

PIMENTA-BUENO, M. (1981b) Os particípios passivos portugueses: verbos, adjetivos ou uma terceira classe? Anais do VI Encontro Nacional de Lingüística. PUCRJ.

PIRES, A. M. G. (1996) As Formas V-DO no Português do Brasil: características sintáticas e semânticas. Dissertação de Mestrado. UnB.

PIRES, N. (1992) Aspectos da Gramática da Língua Jeromiti (Jaboti). Dissertação de Mestrado. UNICAMP.

PIZZINI, Q. A. (1979) Três tipos de orações relativas em português. Anais do I Encontro Nacional de Lingüística, PUC-RJ: 74-84.

PONDÉ, S. (1996) A estrutura argumental nas nominalizações: uma questão lexical. Anais do XXV Seminário do GEL: 702-707.

PONTES, E. (1973) Verbos Auxiliares no Português. (Tese original de 1969) Petrópolis, RJ, Vozes.

(1976) A propósito dos pré-artigos. Anais do I Encontro Nacional de Lingüística. PUC-RJ.

(1987) O Tópico no Português do Brasil, Campinas, Pontes.

PRADO, M. S. (1997) Um estudo sobre o genitivo pré-nominal em português do Brasil. Seminários de Teoria Gramatical. FFLCH-USP.

QUÍCOLI, A. C. (1972) Aspects of Portuguese complementation. State University of New York. Ph. D. Dissertation.

RAMOS, J. (1992) Marcação de Caso e Mudança Sintática: abordagem gerativa e variacionista. Tese de Doutorado. UNICAMP.

(1997a) A sociolingüística paramétrica: Lingüística paramétrica ou variação sintática? Comunicação apresentada no Seminário de Sociolingüística. João Pessoa.

(1997b) O uso das formas você, ocê e cê no Dialeto Mineiro. In: Demerval Hora (org.) Diversidade Lingüística no Brasil. João Pessoa. Idéia Ed. Ltda.

(1997c) Realização morfológica de caso em SNs quantificados no Português do Brasil. UFMG, ms.

RAMOS, R. M. S. (1973) A teoria dos casos na análise do uso das preposições 
em inglês. Letras de Hoje 15: 113-130.

RAPOSO, E. (1986) On the null object in European Portuguese. In: Jaeggli, O. \& C. Silva-Corvalán (orgs.) Studies in Romance Linguistics. Dordrecht, Foris.

(1992) Teoria da Gramática: a Faculdade da Linguagem. Lisboa, Caminho.

RIBEIRO I. (1988) O Papel do Traço [+Acordo] em Construções com Infinitivo Flexionado. Dissertação de Mestrado. UFBA.

(1989) A teoria dos casos e o verbo acreditar. Cadernos de Estudos Lingüísticos 17: 91-108.

(1993) A formação dos tempos compostos: a evolução histórica das formas ter, haver e ser. In: Roberts \& Kato (orgs): 343-386.

(1995) A Sintaxe da Ordem no Português Arcaico: o efeito V2. Tese de Doutorado. UNICAMP.

(1996a) Traços morfológicos fortes e fracos, ordem XVS e o critérioqu. Anais do I Encontro Internacional da ABRALIN: 127-135.

(1996b) A ordem dos constituintes. In: Mattos e Silva, R.V. (org.) $A$ Carta de Caminha: Testemunho Lingüístico de 1500. Salvador, Edufba. RIZZI, L. (1991) Residual verb second and the Wh-criterion. University of Génève Technical Reports in Formal and Computational Linguistics, n. $^{\circ}$ 2.

ROBERTS, I. \& M. A. KATO (1993) Português Brasileiro: uma viagem diacrônica: 409-425. Campinas, SP, Editora da UNICAMP. 2a edição: 1996.

ROBERTS, I. (1993a) Verbs and Diachronic Syntax: A Comparative History of English and French. Dordrecht-Boston-London, Kluwer Academic Publishers.

(1993b) Pósfácio. In: Roberts, I. \& M. A. Kato (orgs.): 409-425.

ROCCA, P. A. (1978) Padrões sintáticos complexos do inglês e do português: análise contrastiva e sugestões de aplicação pedagógica. Dissertação de Mestrado. PUC-SP.

ROCHA, M. L. F. (1990) Sintagma QU- em Interrogativas Indiretas e Relativas Livres do Português. Dissertação de Mestrado. UnB.

RODRIGUES, M. H. N. (1975) Uma análise gerativo-transformacional de estruturas encaixadas em português. Dissertação de Mestrado. PUCCampinas.

ROMUALDO, J. A. (1975) Cláusulas comparativas do português. Dissertação de Mestrado. UNICAMP.

SALIBA, S. M. P. (1983) Algumas funções do "em" no português do Brasil uma análise sintático-semântica. Dissertação de Mestrado. PUCRGS. 
SALLES, H. M. M. L. (1992) Preposições em Português: um estudo preliminar. Dissertação de Mestrado. UnB.

(1996a) Argument licensing in ditransitive constructions. Research papers in Linguistics. Vol. 8. University of Wales, Bangor.

(1996b) Double Objecto Constructions: a Minimalist Approach. Research Papers in Linguistics 8. University of Wales.

(1997) On the correlation between $\mathrm{P}$ (reposition stranding) and $\mathrm{D}$ (ouble $\mathrm{O}$ (bject) C(onstructions). UCW-Bangor/UnB, ms.

SAMARA, S. (1976) Análise das orações relativas introduzidas por onde. Dissertação de mestrado. PUC-SP.

SANTOS, J. S. (1996) Ligação não-Seletiva de Subjuntivos: suas implicações na gramática. Dissertação de Mestrado. UNICAMP.

SARAIVA, M. E. (1979) Movimento de Advérbios de Modo em Português. Dissertação de Mestrado. UFMG.

(1980) O transporte dos advérbios de modo em português. Ensaios de Lingüística 3: 87-96.

(1996) O SN Nulo Objeto em Português: Um Caso de Incorporação Semântica e Sintática. Tese de Doutorado. UFMG.

SCHAFF FILHO, M. (1981) Análise casual do sintagma nominal complexo em português. Dissertação de Mestrado. PUC-RGS.

SCHER, A. P. (1996) As Construções com dois Complementos no inglês e no Português do Brasil: um estudo sintático comparativo. Dissertação de Mestrado. UNICAMP.

(1997) 'Scrambling' determinando o efeito de objeto duplo do Português do Brasil. Anais do I Encontro do CELSUL: 896-905.

SCHLACHTER, E. (1996) A concordância no renano-palatibo: uma interpretação teórica dentro do Minimalismo. Anais do XXV Seminário do GEL: 744-750.

SCHMITZ, J. R. (1977) Análise contrastiva de erros: Estar com- Ter em português e Be-Have no inglês. Revista Brasileira de Lingüística 4 (1). Ano III: 38-48.

SENDAY, D. (1975) Seqüências de clíticos em português. Dissertação de Mestrado. UNICAMP.

SHIBAO, S. (1977) Um estudo do complemento nominal em português. Dissertação de Mestrado. PUC-SP.

SIKANSI, N. S. (1994) A Estrutura das Sentenças com Pronome Interrogativo no Português Brasileiro. Dissertação de Mestrado. UNICAMP.

SILVA, M. (1977) As orações relativas preposicionadas no português coloquial. Dissertação de Mestrado. UnB.

SILVA, M. C. P. de S. (1973) As orações relativas introduzidas por pronome 
"que". Dissertação de Mestrado. PUC-SP.

SILVA, M. P. F. N. (1975) Aspectos da colocação dos pronomes clíticos no dialeto do português falado na cidade do Rio de Janeiro, numa abordagem transformacional. Dissertação de Mestrado. PUC-RJ.

SILVEIRA, G. (1996) O Comportamento Sintático dos Clíticos no Português brasileiro. Dissertação de Mestrado. UFSC.

SILVEIRA, J. R. C., L. SIMÕES, S. ABREU, G. COLLISHONN \& D. LIMA (1994) O infinitivo flexionado em português: um reestudo de Raposo. Letras de Hoje 96: 135-146.

SIMÕES, A. M. (1974) Movimento de quantificadores em português. Dissertação de Mestrado. UNICAMP.

SOUSA, E. (1977) A preposição e os termos da frase. Dissertação de Mestrado. UnB.

STEINER, E. M. (1978) O uso de alguns recursos endofóricos em português. Dissertação de Mestrado. PUC-SP.

SZABO, L. M. (1986) Aquisição de padrões sintáticos em inglês correspondentes a estruturas iniciadas por verbo em português. Dissertação de Mestrado. PUC-SP.

TARALLO, F. (1993) Diagnosticando uma gramática brasileira: o português d'aquém e d'além mar ao final do século XIX. In: Roberts, I. \& M. A. Kato (orgs.): 69-106.

TARALLO, F. \& M. A. KATO (1989) Harmonia trans-sistêmica: variação inter e intra-lingüística. Preedição 5. UNICAMP.

TAVARES de MACEDO, A. (1977) Modelos de análise para o auxiliar em português. Lingüística V. Rio de Janeiro, RJ, Museu Nacional da UFRJ.

TEIXEIRA, R. F. A. (1977) Pronomes pessoais sujeitos em português. Dissertação de Mestrado. UnB.

TONDO, N. V. (1976) Aspectos sintáticos e semânticos da concordância verbal em português. Dissertação de Mestrado. PUC-SP.

TORRES MORAIS, M. A. (1993) Aspectos diacrônicos do movimento do verbo, estrutura da frase e caso nominativo no português do Brasil. In: Roberts, I. \& M. A. Kato (orgs.): 263-306.

(1995) Do Português Clássico ao Português Moderno: um estudo da cliticização e do movimento do verbo. Tese de Doutorado. UNICAMP. (1996) Hipótese para o aparecimento das construções de topicalização na história do português. Anais do XXV Seminário do GEL: 636-640.

(1997) A sintaxe do verbo e clíticos no português. Anais do I Encontro do CELSUL: 793-800.

TRIEWEILER, N. A. (1976) Emprego dos tempos verbais na sintaxe popular. 
Dissertação de Mestrado. PUC-RJ.

VANETTI, L. M. K. (1988) O "Tópico" e o Objeto Nulo no PB. Dissertação de Mestrado. UNICAMP.

VANNUCCHI, J. D. (1977) Sintaxe da gradação do adjetivo em português. Revista Brasileira de Lingüística 4 (2), Ano III: 17-44.

VASCONCELOS, A. G. T. (1976) Uma análise gerativo-transformacional do verbo "Ter". Dissertação de Mestrado. PUC-Campinas.

VEADO, R. A. (1981) Uma proposta que considera a marca de número como constituinte gerado no SN em lugar de traço de nome. Ensaios de Lingüística 3: 102-118.

VIANA, A. M. S. (1995) A Expressão de Atributo na Língua Karajá. Dissertação de Mestrado. UnB.

VIANA, M. L. (1977) As orações relativas do português e do francês: uma análise contrastiva. Dissertação de Mestrado. PUC-RS.

VIEIRA, M. A. R. (1978) A voz passiva num tratamento lexicalista. Dissertação de Mestrado. UFRJ.

VIEIRA, M. D. (1989) O fenômeno da não-configuracionalidade em algumas línguas da família Tupi-Guarani. Comunicação apresentada no Seminário: Sistemas de Marcação de Caso. IEL-UNICAMP, Campinas.

(1995a) The expression of quantificational notions in Asurini do Trocará: against the universality of determiner quantification. In: Bach E, B. Partee, A. Kratzer e E. Jelinek (orgs.) Quantification in Natural languages. Dordrecht, Kluwer.

(1995b) Os parâmetros da configuracionalidade e da projeção e a língua Asurini do Trocará. Revista Latino-Americana de Estudos Etnolingüísticos, Vol. VII: 87-108.

(1997a) Long-distance binding in Mbyá Guarani. Comunicação apresentada no XVI Congresso Internacional de Lingüística. Paris (resumo publicado nos Anais do Congresso).

(1997b) A derivação da incorporação nominal na língua Tupinambá (Tupi-Guarani). Atas das II Jornadas de Lingüística Aborigen. Universidade de Buenos Aires.

(1997c) Para uma análise das sentenças possessivas do tipo bahuvrihi, em línguas da família Tupi-Guarani. Comunicação apresentada no 490 Congresso Internacional de Americanistas. Quito.

VILANOVA, L. E. (1989) Mudanças em X-barra na História do Francês. Dissertação de Mestrado. UFRJ.

(1989) Mudanças na X-barra na história do francês. Dissertação de Mestrado. UFRJ.

VIOTTI, E. (1997) A predicação e as relações temáticas nas sentenças com o 
verbo ter. Seminários de Teoria Gramatical 1. FFLCH-USP.

VITRAL, L. (1992) Structure de la Proposition, et Syntaxe du Movement du Verbe en Portugais Brésilien. Tese de Doutorado. Un. Paris VIII.

(1994) Estruturas VS e concordância verbal: uma perspectiva Minimalista. In: Anais do I Encontro Internacional da ABRALIN. Salvador.

(1996) A forma cê e a noção de gramaticalização. Revista de Estudos da Linguagem, Ano 5 (4): 115-124. (1997) A Negação: Teoria de checagem e mudança lingüística. UFMG, ms.

VOTRE, S. J. (1976) Para uma análise semântica do português. Letras de Hoje 26: $41-56$.

WALDREP, J. W. (1981) Um estudo sintático das orações finais no português. Dissertação de Mestrado. UNICAMP.

WEICHEL, S. (1997) A Ordem dos Constituintes do Alemão. Dissertação de Mestrado. UFSC.

WHEELER, D. (1981) Object deletion in Portuguese. In: Lantolf \& Stone (orgs.) Current Research in Romance Languages. Filadelfia, John Benjamins.

WHITAKER FRANCHI, R. C. M. (1989) As Construções Ergativas: um estudo semântico e sintático. Dissertação de Mestrado. UNICAMP.

ZUIANI, M. R. (1988) Um Estudo da Forma e Interpretação das Sentenças Relativas no Português Brasileiro. Dissertação de Mestrado. UNICAMP. 